\title{
Preparations for Water Sampling
}

Chapter 1 of

Section A, National Field Manual for the Collection of Water-Quality Data Book 9, Handbooks for Water-Resources Investigations
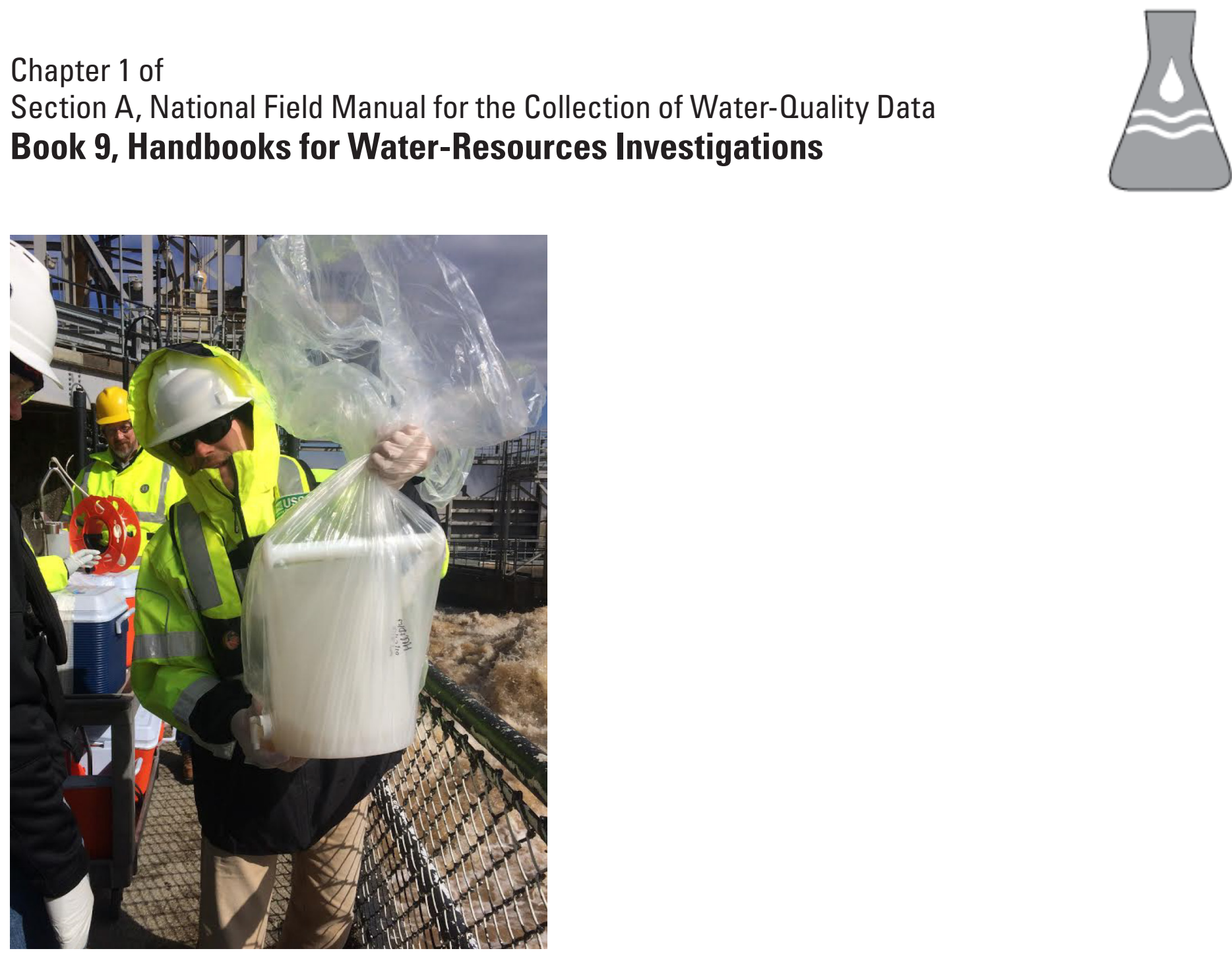

Techniques and Methods 9-A1

Supersedes USGS Techniques of Water-Resources Investigations, Book 9, Chapter A1, Version 2.0 
Cover: Photograph showing preparations for collection and processing of water-quality samples at Conowingo Dam, Md. (USGS monitoring station 01578310). Photograph by Brenda Majedi, U.S. Geological Survey. 


\section{Preparations for Water Sampling}

By U.S. Geological Survey

Chapter 1 of

Section A, National Field Manual for the Collection of Water-Quality Data

Book 9, Handbooks for Water-Resources Investigations

Techniques and Methods 9-A1

Supersedes USGS Techniques of Water-Resources Investigations,

Book 9, Chapter A1, version 2.0

U.S. Department of the Interior

U.S. Geological Survey 


\section{U.S. Department of the Interior RYAN K. ZINKE, Secretary}

\section{U.S. Geological Survey James F. Reilly II, Director}

\section{U.S. Geological Survey, Reston, Virginia}

First release: 1998, online as Techniques of Water-Resources Investigations, book 9 , chapter $A 1$, version 1.0

Revised: 2005, online as TWRI, book 9, chapter A1, version 2.0

Revised: November 2018, online as Techniques and Methods, book 9, chapter A1

\footnotetext{
For more information on the USGS - the Federal source for science about the Earth, its natural and living resources, natural hazards, and the environment-visit https://www.usgs.gov or call 1-888-ASK-USGS.

For an overview of USGS information products, including maps, imagery, and publications, visit https://store.usgs.gov.
}

\footnotetext{
Any use of trade, firm, or product names is for descriptive purposes only and does not imply endorsement by the U.S. Government.

Although this information product, for the most part, is in the public domain, it also may contain copyrighted materials as noted in the text. Permission to reproduce copyrighted items must be secured from the copyright owner.

Suggested citation:

U.S. Geological Survey, 2018, Preparations for water sampling: U.S. Geological Survey Techniques and Methods, book 9, chap. A1, 42 p., https://doi.org/10.3133/tm9A1. [Supersedes USGS Techniques of Water-Resources Investigations, book 9 , chap. A1, version 2.0.]
}

ISSN 2328-7055 (online) 


\section{Contents}

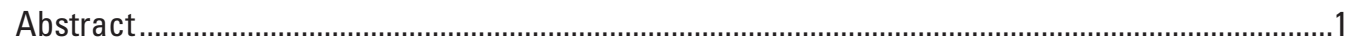

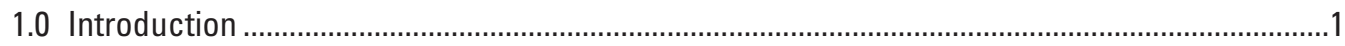

1.1 Roles and Responsibilities for Water-Quality Personnel ......................................................

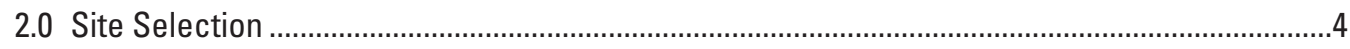

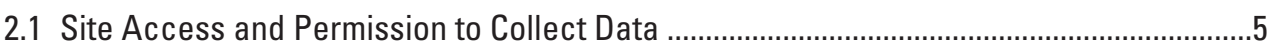

2.2 Selection of Surface-Water Sites for Water-Quality Sampling ...........................................5

2.2.1 Site Selection in Flowing Water .........................................................................

2.2.2 Site Selection in Still Water ..................................................................................

2.2.3 Site Selection in Tidal Waters .............................................................................

2.3 Selecting Groundwater Sites ......................................................................................

2.3.1 Reconnaissance for Selection of a Groundwater-Monitoring Station....................7

2.3.2 Reconnaissance for Selecting Existing Wells .......................................................

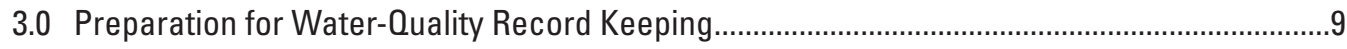

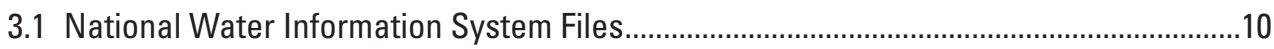

3.1.1 Establishing a New Site in NWIS...................................................................10

3.1.2 Documentation of an Existing SITEFILE in NWIS ..................................................11

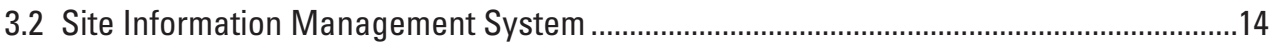

3.3 Forms for Field Notes, Analytical Services, and Chain of Custody .................................14

3.3.1 Personal Computer Field Form ...........................................................................14

4.0 The Project Work Plan ............................................................................................... 15

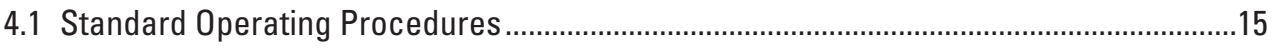

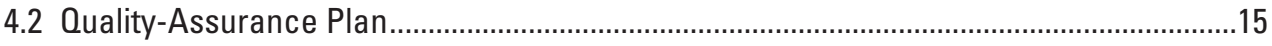

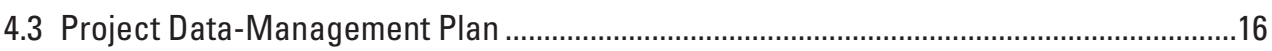

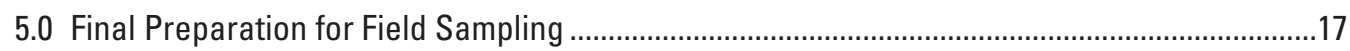

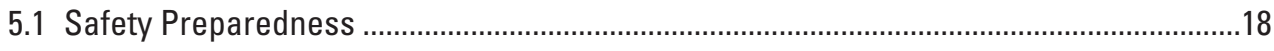

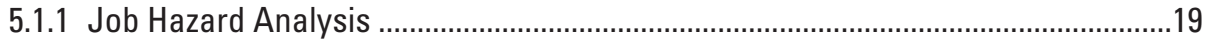

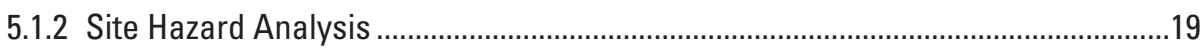

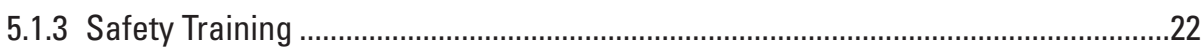

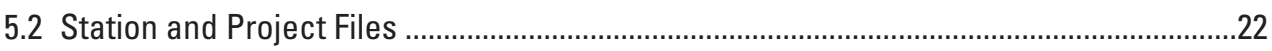

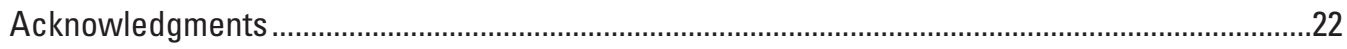

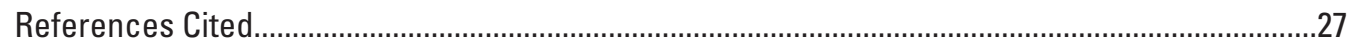

Appendix A. Forms to Establish a New Site in the Groundwater Site Inventory ............................31 


\section{Figures}

1-1. Example of a traffic-control safety plan. (Modified from U.S. Geological Survey, 2014b)

1-2. Examples of maps to document site locations: A, site-location map for Rock Creek Park in Washington, D.C., and B, sketch of a well site

1-A.1. Form 9-1904-A-U.S. Geological Survey schedule for establishing a new surface-water site in the Groundwater Site Inventory (GWSI).

1-A.2. Form 9-1904-A-U.S. Geological Survey schedule for establishing a new groundwater site in the Groundwater Site Inventory (GWSI)

\section{Tables}

1-1. Example of groundwater site inventory activities

1-2. Minimum information required for electronic storage of a surface-water SITEFILE record in the GWSI, and surface-water-quality data in OWDATA of the USGS NWIS.

1-3. Minimum information required for electronic storage of a surface-water SITEFILE record in the GWSI, and surface-water-quality data in OWDATA of the USGS NWIS.

1-4. Checklist for preparation to conduct field sampling

1-5. Example-Job Hazard Analysis for water-quality measurements in the field 19

1-6. Information to be included in a station folder for surface-water-quality monitoring stations

1-7. Information to be included in a station folder or well file for groundwater-quality monitoring stations 


\section{Conversion Factors}

U.S. customary units to International System of Units

\begin{tabular}{|c|c|c|}
\hline Multiply & By & To obtain \\
\hline \multicolumn{3}{|c|}{ Length } \\
\hline inch (in.) & 2.54 & centimeter $(\mathrm{cm})$ \\
\hline inch (in.) & 25.4 & millimeter (mm) \\
\hline foot (ft) & 0.3048 & meter (m) \\
\hline mile (mi) & 1.609 & kilometer (km) \\
\hline \multicolumn{3}{|c|}{ Volume } \\
\hline gallon (gal) & 3.785 & liter (L) \\
\hline gallon (gal) & 0.003785 & cubic meter $\left(\mathrm{m}^{3}\right)$ \\
\hline gallon (gal) & 3.785 & cubic decimeter $\left(\mathrm{dm}^{3}\right)$ \\
\hline million gallons (Mgal) & 3,785 & cubic meter $\left(\mathrm{m}^{3}\right)$ \\
\hline
\end{tabular}

\section{Datum}

Altitude, as used in this report, refers to distance above the vertical datum.

\section{Abbreviations and Symbols}

$\begin{array}{ll}\text { ASR } & \text { analytical services request form } \\ \text { BOS } & \text { Branch of Quality Systems (USGS) } \\ \text { COC } & \text { chain of custody } \\ \text { CRP } & \text { continuous records processing } \\ \text { DIC } & \text { dissolved inorganic carbon } \\ \text { DIW } & \begin{array}{l}\text { quality-assured deionized water with resistance greater than or equal to } 18 \\ \text { megaohms (M } \Omega \text { ) }\end{array} \\ \text { DOC } & \text { dissolved organic carbon } \\ \text { DOD } & \text { U.S. Department of Defense } \\ \text { EDI } & \text { equal-discharge increment, isokinetic sampling method } \\ \text { EPA } & \text { U.S. Environmental Protection Agency } \\ \text { EWI } & \text { equal-width increment, isokinetic sampling method } \\ \text { GPS } & \text { global positioning system } \\ \text { GWPD } & \text { Groundwater Technical Procedures Document (Cunningham and Schalk, 2011) } \\ \text { GWSI } & \text { Groundwater Site Inventory (USGS NWIS database for site information and } \\ & \text { groundwater data) }\end{array}$




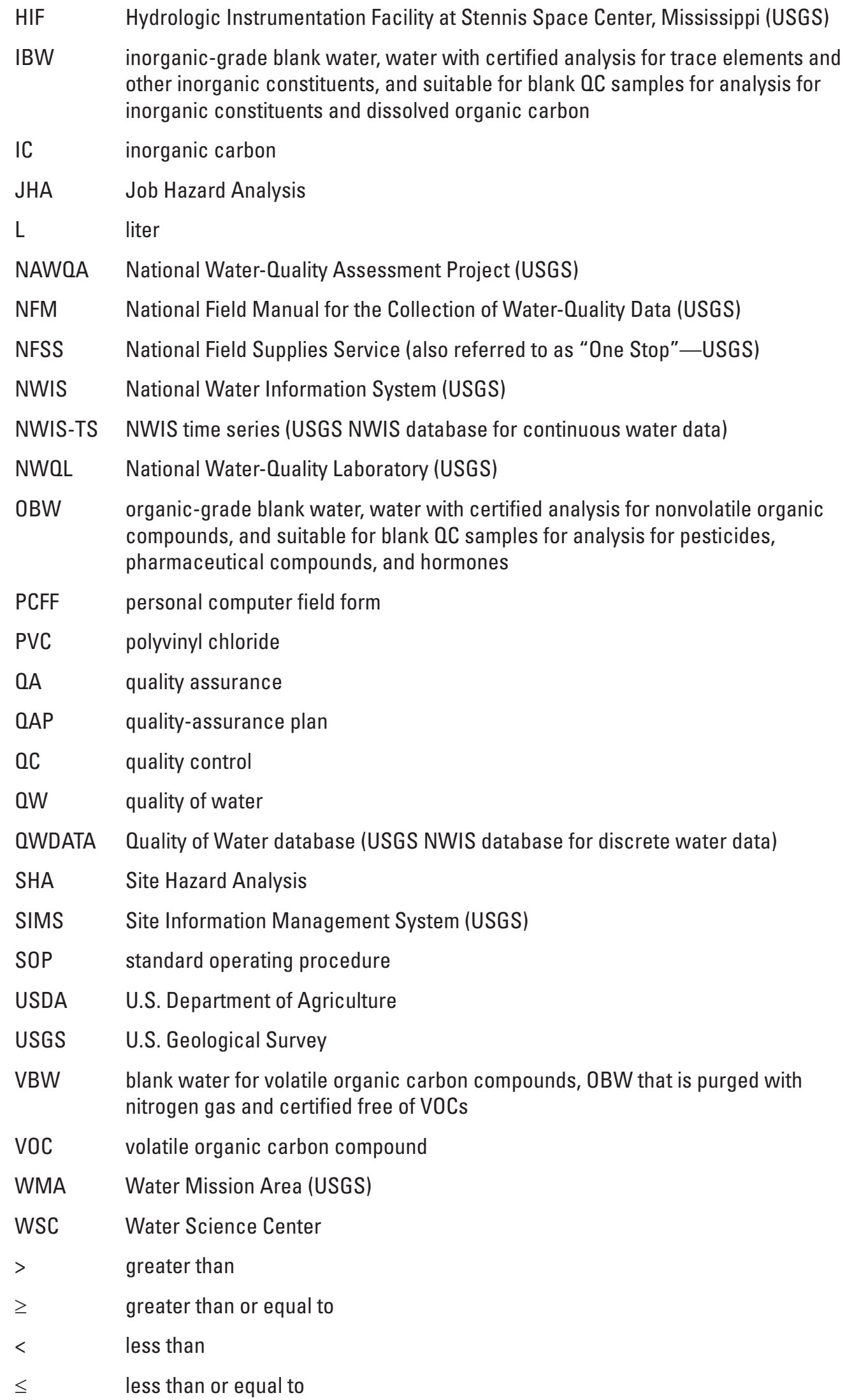




\section{Requirements and Recommendations}

As used in the U.S. Geological Survey (USGS) "National Field Manual for the Collection of Water-Quality Data" (NFM), the terms "required" and "recommended" have the USGSspecific meanings described below:

- The terms "require," "required," and "requirements" in reference to USGS protocols indicate that USGS Water Mission Area (WMA) policy has been established on the basis of research or consensus of the technical staff, and has been reviewed by waterquality specialists and other professionals having the appropriate expertise. Technical memorandums and other documents that define USGS WMA policy are cited in the NFM. USGS field personnel are instructed to use required equipment and procedures as described in the NFM. Departure from or modifications to stipulated requirements, if necessary for accomplishing specific data-quality requirements or study objectives, must be independently quality assured and documented (Office of Water Quality Technical Memorandum 2002.13-U.S. Geological Survey, 2002).

- The terms "recommend," "recommended," and "recommendation" indicate that, on the basis of research or consensus, there are several acceptable alternatives to a given procedure or equipment selection in the NFM. Relevant technical memorandums and publications pertinent to such recommendations are cited in the NFM to the extent that such documents are available. Specific requirements, data-quality objectives, or other constraints of a project may affect the choice of recommended equipment or procedures. Selection from among the recommended alternatives should be based on referenced research and sound field judgment, and reasons for the selection must be documented. Departures from or modifications to the recommended procedures must be independently quality assured and documented (Office of Water Quality Technical Memorandum 2002.13-U.S. Geological Survey, 2002). 


\title{
Chapter A1. Preparations for Water Sampling
}

\author{
By U.S. Geological Survey
}

\section{Abstract}

The "National Field Manual for the Collection of WaterQuality Data" (NFM) provides guidelines and procedures for U.S. Geological Survey (USGS) personnel who collect data used to assess the quality of the Nation's surface-water and groundwater resources. This chapter, NFM A1, provides an overview of preparations for water sampling, which includes site reconnaissance, project work plans, quality-assurance plans, basic equipment and supplies needed for fieldwork, safety precautions, and planning for data management. It updates and supersedes USGS Techniques of Water-Resources Investigations, book 9, chapter A1, version 2.0, by F.D. Wilde.

Before 2017, the NFM chapters were released in the USGS Techniques of Water-Resources Investigations series. Effective in 2018, new and revised NFM chapters are being released in the USGS Techniques and Methods series; this series change does not affect the content and format of the NFM. More information is in the general introduction to the NFM (USGS Techniques and Methods, book 9, chapter A0) at https://doi.org/10.3133/tm9A0. The authoritative current versions of NFM chapters are available in the USGS Publications Warehouse at https://pubs.er.usgs.gov/. Comments, questions, and suggestions related to the NFM can be addressed to nfm-owq@usgs.gov.

\subsection{Introduction}

The "National Field Manual for the Collection of WaterQuality Data" (NFM) is the official and citable protocol for the collection of water-quality data by the Water Mission Area (WMA) of the U.S. Geological Survey (USGS). The NFM provides guidelines and procedures for USGS personnel who collect data for water quality in surface water and groundwater, with detailed, comprehensive, and citable procedures. National USGS program and project personnel who collect water-quality data, as well as those in USGS Water Science Centers (WSCs), and including projects supported by the USGS Cooperative program, are mandated to use protocols provided in the NFM (USGS Office of WaterQuality Technical Memorandum 2002.13-U.S. Geological
Survey, 2002). Formal training, as provided in the USGS class "Field Water-Quality Methods for Groundwater and Surface Water," and field apprenticeships supplement the information provided in the NFM and are needed to collect unbiased, high-quality data.

The USGS National Field Manual provides detailed, comprehensive, and citable procedures for monitoring the quality of surface water and groundwater. Formal training and field apprenticeships supplement the information provided in the NFM.

Chapter A1 of the NFM addresses the initial preparations for making water-quality measurements and collecting samples for water quality at surface-water and groundwater sites. All of the preparations fall within an individual project work plan that provides the project objectives and methods to guide the upcoming fieldwork and data processing.

This chapter updates and supersedes USGS Techniques of Water-Resources Investigations, book 9, chapter A1, version 2.0 (Wilde, 2005). It provides guidance for the following procedures - reconnaissance and selection of waterquality-monitoring sites, the creation of station folders that contain supporting information on sites and data-collection activities, project work plans, quality-assurance plans, basic equipment and supplies needed for fieldwork, safety precautions, accurate and efficient record keeping, and planning for data management. Thorough planning during the initial phases of a water-quality study will result in timely and reliable products.

Before 2017, the USGS NFM chapters were released in the USGS Techniques of Water-Resources Investigations series. Effective in 2018, new and revised NFM chapters are being released in the USGS Techniques and Methods series; this series change does not affect the content and format of the NFM. More information is in the general introduction to the NFM (USGS Techniques and Methods, book 9, chapter A0 - U.S. Geological Survey, 2018a) at https://doi.org/10.3133/tm9A0. The authoritative current versions of NFM chapters are available in the USGS Publications Warehouse at https://pubs.er.usgs.gov. Comments, questions, and suggestions related to the NFM can be addressed to nfm-owq@usgs.gov. 


\subsection{Roles and Responsibilities for Water-Quality Personnel}

Fundamental to water-quality sampling is the fact that the analytical results can be no better than the sample on which the analysis was performed. Therefore, it is critical that each step in the process of collecting and processing water-quality samples is carried out by using approved USGS protocols while staying within the framework of project objectives. Protocols and project objectives must be documented to ensure accuracy and timeliness of the data. Each member of a USGS water-quality team plays an important role in both the process of collecting samples for analysis of water quality, and managing resulting data in the National Water Information System (NWIS). USGS field personnel have the ultimate responsibility for the high quality and objectivity of USGS water-quality data. Communication and collaboration among field, laboratory, and project personnel are essential to producing valid data from the sampling effort.

Chapter 502.2 of the USGS Manual on Fundamental Science Practices (U.S. Geological Survey, 2011) covers USGS policies for planning and conducting data collection and research. USGS personnel who conduct fieldwork for water resources should be familiar with this document as well as other WMA policies and protocols covered in the NFM. See table 1-1 for examples of groundwater site inventory activities.

Each member of a USGS water-quality team plays an important role in the process of collecting samples for analysis of water quality and managing resulting data in NWIS.

Table 1-1. Example of groundwater site inventory activities.

[USGS, U.S. Geological Survey]

\section{Before the site visit}

Review considerations for well selection and installation (U.S. Geological Survey, 2006a; Lapham and others, 1997).

Review background information.

Obtain permission to gain access to the site and to collect samples from the well.

Update well files - record changes in ownership and land use.

Contact utility companies (gas, water, and electric) before digging or drilling.

Determine whether the pump may or may not be removed from the well by field personnel (removal is not recommended, as personal safety could be compromised). The owner's permission is required to remove a pump - the USGS could be liable for damage to pump or well.

Obtain information needed about the site that could interfere with or interrupt sampling. For example:

- Hours of pump operation and scheduled downtime.

- Pumping rate or rates.

- Holding tanks or chemical treatments.

- Electrical service to the site.

- Scheduled maintenance for pumps or related equipment.

- Scheduled site maintenance, such as painting, construction, and defoliation.

- Seasonal water-level declines that make the well unusable.

- Times of denied access - for example, no access while the owner is out of town.

- Special site-access needs - for example, clearance with a site owner or site operator, keys to unlock access to the site, animals.

- Restrictions on the location.

\section{Before and during the site visit}

Record conditions that could compromise study objectives, including potential point or nonpoint sources of contamination. For example:

- Nearby wells that could affect well hydraulics.

- Condition of well, such as rusting or punctured casing or poor surface seal.

- Has the well been adequately developed? Could well-development artifacts compromise sample integrity?

- Land use and land cover.

- Application of salt on nearby roads during winter, or application or use of herbicides and pesticides.

- Landfills or other waste-management facilities.

- Industrial, commercial, and agricultural complexes and discharges. 
Table 1-1. Example of groundwater site inventory activities.-Continued

[USGS, U.S. Geological Survey]

\section{During the site visit}

Measure water level in each well. Record water-level measurements on the appropriate field form(s), and in the Groundwater Site Inventory (GWSI) and Quality of Water Data (QWDATA) databases.

Identify potential difficulties with the type of equipment and sample-collection methodology to be used. (Note that sampling plans will have to be modified accordingly.)

Update field folders.

- Note site conditions that could affect the quality of data collected from that well.

- Note changes in land use.

Verify well identification number and make sure that it is clearly and permanently labeled.

- Check that identification number corresponds with number in the field folder and on site and location maps.

- Correct any mistakes or uncertainty about well identification and well location.

Verify type of pump, well diameter, and use of holding tanks, pressure tanks, chemical treatments.

- Check whether oil is floating on the water column in a well equipped with an oil-lubricated pump.

- Make sure that the downhole treatment system is turned off before collecting water samples.

- Determine whether the intended sampling device is suitable for use.

Establish optimum pumping rates for purging and sample collection and decide where to route excess discharge.

- Adjust pumping rate to ensure adequate purging of the well without entrainment of atmospheric gases due to excessive drawdown.

- Route water away from the well to prevent (1) creating muddy and slippery conditions and (2) damage to or defacement of the property to which you were granted access.

Check that well structure is intact.

- Wells used for groundwater studies should be "sounded" annually to check whether depth to bottom corresponds with well-construction information or whether the well is filling with loose materials (Lapham and others, 1997). A decrease in depth to bottom could indicate that the well casing is collapsing, that there is a breach or corrosion of well screen or casing, or that the well is improperly designed to retain aquifer materials.

- Borehole caliper and downhole-camera video logs can identify a damaged or broken well casing. A downhole camera can identify a plugged screen or accumulation of sediment in the well.

- Aquifer tests, such as slug tests, can be used to check the hydraulic connection between the well and the aquifer.

- The surface seal of a U.S. Geological Survey monitoring well should be intact and the well should be capped. Concrete pad should be repaired if cracked or separated from outer casing. A tight-fitting well cap should have a small ventilation hole.

Check well access for sample-collection points.

- Sample-collection points need to be near the wellhead, ahead of where water enters pressure tanks, holding tanks, or treatment systems.

- At wells where an access point close to the well is not available, it might be possible to install a hose bib or tap at the wellhead. Because it usually is not possible to control the pumping rate of a supply well, the field person may need to set up a hose-and-valve system to control the rate at which water is sampled and to reduce the likelihood of backflow of water stored in plumbing lines.

Check well access for water-level measurements. The construction of some supply wells makes water-level measurements difficult or impossible.

- Although it is often possible to slip a weighted steel or electric well tape below the pump to obtain a water-level measurement, the pump can be damaged if the weight or tape becomes entangled in the pump. The weight should be attached so that it will snap off the tape under stress.

- Water levels can be estimated through the air line on some wells.

- Sometimes field personnel are permitted to remove the pump from the well to obtain a measurement. However, pump removal can be difficult and time consuming, is potentially unsafe, and could damage the pump or well.

- A note should be made in the well file if there is no access for a depth measurement. 


\section{- Responsibilities of field personnel-}

- Field personnel must maintain their professional and technical expertise in all water-quality-sampling and database techniques relevant to the needs of their individual data-quality objectives.

- They ensure that USGS protocols are followed for all water-quality monitoring and related activities.

- They adhere to project work plans, standard operating procedures (SOPs), and quality-assurance plans (QAPs).

- They communicate in a timely fashion with project managers and supervisors on the routine progress of all water-quality activities as well as abnormal situations or problems that may arise.

- They document and obtain approval for any deviations from USGS official protocols.

- They network with personnel from other projects to optimize productivity of projects and quality of USGS products.

\section{- Responsibilities of project managers-}

- Project managers direct and manage project activities in the field and laboratory. These tasks include the management, analysis, and archiving of data.

- They ensure that monitoring and data analysis for water-quality activities meet the needs of the Federal Government, the USGS, the Water Science Center (WSC), cooperating State and local agencies, and the public.

- They develop a written work plan for the project that includes or refers to standard USGS-approved protocols, a schedule for completing tasks and deliverables, and a budget.

- They develop a project QAP, with guidance, as appropriate, from water-quality specialists and the USGS Office of Quality Assurance. The project QAP is referenced to the WSC QAP and USGS standards.

- They ensure that all aspects of the project SOPs and QAP are understood and followed by their project personnel.

- They network with personnel from other projects to optimize productivity of projects and quality of all USGS products.

\section{- Responsibilities of project supervisors-}

- Project supervisors are informed about each project as soon as a proposal is written and are kept informed of progress during the timespan of each project.
- They review project proposals to ensure that they are appropriate to the USGS mission and that the project objectives are achievable within the resources of the project.

- They review project work plans, budgets, timelines, and deliverables and conduct regular project reviews to assure that projects are meeting their goals.

- They ensure that staff and resources are available to achieve project objectives in a timely manner.

\subsection{Site Selection}

Site selection occurs early in the process of project planning. Considerations for site selection include the appropriate quantity and locations of sampling sites, data-quality objectives, types of data and samples to be collected, site accessibility, safety, and project budget. The process of selecting sites for water-quality monitoring begins with assembling and reviewing all available relevant information for the study area and data collection.

\section{- Site-selection process}

- Review the project plan and understand the purpose for which the various types of data will be collected.

- Compile a surface-water and (or) groundwater site inventory for the study area from the USGS National Water Information System (NWIS) SITEFILE, which is managed with the Groundwater Site Inventory (GWSI) subsystem software. In addition to the SITEFILE, the GWSI contains site-characteristic information for groundwater sites, such as well construction and casing information. Using the site inventory, identify existing gage and well sites and, as appropriate, compile background information and available records for those sites.

- Review historical information in NWIS, the USGS Site Information Management System (SIMS), and other data sources. Note site location, description, and access.

- Review any previously collected physical, chemical, and biological data that may be stored in the Quality of Water Database (QWDATA), the discrete waterquality subsystem of NWIS.

- Make field reconnaissance trips prior to selecting sampling sites to verify information in the NWIS and SIMS databases. Evaluate each potential location with respect to project needs. During reconnaissance trips, verify gage and well locations and construction details. 
- Determine or confirm latitude and longitude at each potential location by using a global positioning system (GPS), maps, and (or) landsurvey techniques.

- Speak with staff who have knowledge of and familiarity with the selected sites.

- Verify that the selected sites are representative of the system intended for study.

\subsection{Site Access and Permission to Collect Data}

USGS policy specifies that permission must be secured before entering public or private property to select sampling sites, install wells, or collect samples (USGS Water Resources Division Memorandum 90.34-U.S. Geological Survey, 1990). Permission can be granted by a landowner or other responsible party. The USGS preferred business practice is to obtain permission in writing; however, oral permission may be used if it is documented by a USGS representative.

- USGS guidance documents and forms for obtaining permission to access and work on property-

- Agreement forms for gaging-station and observation-well installations or transfers (see USGS Office of Ground Water (OGW) Technical Memorandum 2003.03-U.S. Geological Survey, 2003)

- Groundwater Technical Procedures Document (GWPD) 15 (Cunningham and Schalk, 2011) provides guidance and access to the following forms:

- Permission to collect water samples (see USGS Water Resources Division Memorandum 90.34U.S. Geological Survey, 1990)

- Well drilling/sample agreement forms (see USGS Water Resources Division Memorandum 94.08U.S. Geological Survey, 1994)

- Well Transfer Agreement (Form 9-3106 in USGS Water Resources Division Memorandum 87.17U.S. Geological Survey, 1987)

- Format for letter requesting permission to enter private property (see USGS Manual, chapter 500.11, fig. 500.11.1-U.S. Geological Survey, 2008b)

- Documentation of oral permission to access private lands (see USGS Manual, chapter 500.11, fig. 500.11.2-U.S. Geological Survey, 2008b)

Field staff must acquire a knowledge of any applicable Tribal, State, and (or) local laws requiring notification before engaging in any digging, drilling, trenching, or other earthmoving activities ("call before you dig"). Review special requirements for managing investigation-derived wastes (including purge water from wells), limitations on noise levels, and prohibitions against disturbing or removing sensitive or culturally important animals, plants, rocks, or artifacts. Document any site-access limitations such as keys needed, pets on property, scheduled maintenance times that might interfere with sampling such as pump downtime, construction, pesticide spraying, and so forth. In addition, restrictions set by the landowner, such as dates or times not allowed, locations where utility vehicles are not allowed, and so forth, must be documented and observed.

\subsection{Selection of Surface-Water Sites for Water- Quality Sampling}

Field personnel must select the points or transects at which samples will be collected. In most bodies of flowing or still water, a single sampling site or point does not adequately represent the entire stream segment with respect to physical properties, chemical constituents, or biological communities. Location, distribution, and number of surface-water sampling points can affect the quality and applicability of the resulting data. Guidelines for selecting flowing-water and still-water sites are described in this section.

\section{- When selecting surface-water-quality sampling} sites-

- Evaluate each potential location for representativeness of the samples collected with respect to the larger aquatic system. For example, a river confluence above the site or a nearby weir may affect mixing at the cross section along which samples are collected.

- Consider physical, chemical, and biological characteristics of the area, such as size and shape, land use, tributary and runoff characteristics, geology, storm drains, point and nonpoint sources of contamination, hydraulic conditions, climate, water depth, and fluvial sediment-transport characteristics.

- Note conditions that could affect sampling operations, such as the seasonal high or low streamflow or site-access peculiarities. Verify that sampling transects can be accessed during all typical and extreme flow and weather conditions.

- Evaluate potential sources of contamination at the site, on the basis of target analytes ${ }^{1}$ to be determined.

\footnotetext{
1"Target analyte" refers to any chemical or biological substance for which concentrations in a sample will be determined. Target analytes do not include field-measured properties such as temperature, specific electrical conductance (conductivity), dissolved-oxygen concentration, $\mathrm{pH}$, Eh, alkalinity, color, or turbidity. In the "Concise Chemical and Technical Dictionary," 4th edition (Bennett, 1986, p. 99), "analyte" is defined as a "substance being determined in an analysis."
} 
- Document potential sources of electrical power and phone-line communications. Contact local utility companies before starting any digging or drilling. Determine whether cellphone technology will be accessible at the site, or the location of the nearest access to a cellular signal or landline.

- Consider the study objectives, types of data needed, equipment needs, and sampling methods.

\subsubsection{Site Selection in Flowing Water}

Flowing water can refer to streams (fast or slow, intermittent, ephemeral, or perennial), springs, canals, ditches, and flumes of all sizes and shapes, or to any other surface feature in which water is moving in a consistent direction. Reservoirs and embayments also may have flowing water.

\section{- Flowing-water sampling sites optimally are} located-

- At or near a streamgaging station, to obtain concurrent surface-water discharge data for computing constituent-transport loads and to determine discharge/constituent-concentration relations. If a streamgaging station is not at or near the sampling site or if discharge cannot be rated or estimated with sufficient accuracy, then discharge must be measured at the time of sampling.

- In straight reaches having uniform flow and a stable bottom contour. Document shifting bars that may alter the stream flow regime over time.

-Where constituents are well mixed along the cross section.

- Far enough above and below confluences of streamflow or point sources of contamination to avoid sampling at a cross section where flows are poorly mixed or not unidirectional.

- At a stream reach where representative samples can be collected safely during all flow regimes.

- CAUTION: Any stream, including an ephemeral or intermittent stream, can rapidly become too deep or too swift to wade safely. Before entering the stream, confirm that it can be safely navigated.

- In stream reaches upstream from bridges or other structures, to avoid contamination from the structure or from a road surface.

- In unidirectional flow that does not include eddies. (If eddies are present within the channel, make note of the condition, and sample only where the flow is unidirectional.)
- At or near a location where other data are collected and (or) for which historical data are available.

After tentative selection of a sampling site, develop a preliminary profile of field measurements such as temperature, specific conductance, and turbidity at various locations along the cross section (NFM chapters A4 and A6). The preferred sampling method and number of vertical profiles to be sampled within the stream cross section depend on stream homogeneity as indicated by the field-measurement profile and stream discharge, as well as study objectives. Note that the field-measurement profile is a useful guideline, but might not be representative of chemical homogeneity for the analytes of interest; therefore, this assumption should be tested during the early phases of data collection. Moving to a sampling site upstream or downstream may be necessary to adjust for seasonal variation or extreme flow conditions.

Sampling at ephemeral stream sites may need additional planning and examination to account for changing conditions during the study. Optimal conditions may not always be met as a result of safety and access considerations, but the effects of local conditions on the data must be considered before sampling begins. Detailed observations and measurements of sources of variability over a stream reach are needed to ensure that water-quality samples will be representative of the entire system. At all streams, be observant of the potential for rapidly changing conditions, such as flash flooding or runoff from urban storm drains.

Optimal conditions may not always be met as a result of safety and access considerations, but the effects of local conditions on the data must be considered before sampling begins. Detailed observations and measurements of sources of variability over a stream reach are needed to ensure that water-quality samples will be representative of the entire system.

\subsubsection{Site Selection in Still Water}

Still-water sites refer to sites such as lakes, reservoirs, ponds, swamps, marshes, riverine backwaters, or any other body of surface water where water is not flowing.

- Considerations for selecting still-water sampling sites-

- Use in situ field measurements to determine the vertical and lateral distribution of water quality. Because water is not moving, these systems commonly become stratified and water quality can vary greatly among the stratified sectors.

- Selection of sampling points will depend on the goals of the project. Because stratified layers shift over time, ensure that appropriate sampling points are maintained and verified over the duration of the project. 
- Avoid areas near structures such as harbors, boat ramps, piers, fuel docks, and moored houseboats (to avoid point sources of contamination), unless these structures are targeted for the study.

- Select sites with a record of historical data, if possible.

\subsubsection{Site Selection in Tidal Waters}

Tidally affected waters present a unique challenge to water-quality data collection, as a result of semidiurnal changes in stream velocity and direction. Flow may be unidirectional in either direction or still, but will vary over time. Tidally influenced changes in stream velocity and direction cause difficulty in determining the directional flux of contaminants through the river cross section. Furthermore, the water column at tidal stations may be stratified if freshwater is flowing into and over denser saltwater. The location of the density gradient will move over the tidal cycle. Preferred sampling locations for measuring contaminant loads and fluxes in streams typically are above the influence of tide to avoid this extra source of variability.

- Considerations for selecting sampling sites that are influenced by tide include-

- If stream discharge is required at a tidal site, then flow velocity should be determined with a continuous acoustic velocity meter and stage measurements to capture semidiurnal variability. Discharge at tidally affected stations cannot be computed from a traditional stage-discharge relation, and estimates of fluxes of contaminants are more complex than those for unidirectional flow. Office of Surface Water Technical Memorandum 2010.08 (U.S. Geological Survey, 2010b) provides guidance for collecting and processing discharge and stage data in tidally influenced locations.

- Sampling locations must be evaluated for variability in vertical stratification as well as along the stream transect. Storm surge and tidal fluctuations will shift the location of the stratified interface, both vertically and in the upstream/downstream directions.

- If permanent equipment such as a water-quality monitor or autosampler is to be deployed at the station, the full range of tidal ebb and flow must be determined to locate the appropriate depth of deployment.

\subsection{Selecting Groundwater Sites}

Groundwater is typically sampled either from various types of existing wells or from new wells that are installed specifically for a study.

\section{- Three basic types of wells are used to sample groundwater for analysis of water quality-}

- Supply wells are installed primarily for supply of water for public, irrigation, domestic, commercial, or industrial water use and are typically equipped with a dedicated high-capacity pump.

- Observation wells are wells or piezometers that are installed (typically without a dedicated pump) for the purpose of collecting hydrologic data. The term has generally been applied to wells installed to observe and determine hydrologic characteristics of an aquifer (Lapham and others, 1997).

- Monitoring wells are observation wells that are installed specifically to assess the physical, chemical, and biological characteristics of the aquifer. Low-capacity portable pumps are commonly used for sampling, but monitoring wells can be equipped with a dedicated pump.

Information about each site and well is compiled prior to and during reconnaissance visits, well installation, and subsequent data-collection activities. In the office, identify existing well sites in the GWSI and compile background information for those wells. The field inventory, performed during reconnaissance visits, can then be completed to confirm well locations, construction details, and the suitability of wells with respect to study objectives.

\subsubsection{Reconnaissance for Selection of a Groundwater-Monitoring Station}

The field team critically evaluates candidate wells to determine whether they will yield samples that are representative of the environmental conditions targeted for study and data that will accomplish the project goals. Site reconnaissance is used to verify the location and condition of wells, evaluate site characteristics, determine whether adjustments to sampling plans are needed, and ensure efficiency for future field operations. Site reconnaissance also can be used to identify areas of groundwater recharge and discharge, test field equipment, test well-purging and sampling procedures, conduct aquifer tests, make preliminary field measurements, and conduct initial screening for target analytes.

- When selecting the location of any new or existing well, consider the following (modified from Lapham and others, 1997) -

- Confirm that the location conforms to the network design of the study, with respect to areal and depth distribution.

- Document land-use/land-cover characteristics of the watershed with respect to study objectives and potential effects on groundwater. Consider the 
effects of features such as landfills, waste-disposal or industrial sites, storage tanks, agriculture, discharge points, and potential seasonal applications of road salts, pesticides, fertilizers, or manure.

- Review subsurface geology and verify that the existing or newly developed well is within the desired geologic units.

- Evaluate the site for accessibility with respect to equipment needed for well installation and sample collection.

- Measure and record the water level in existing wells by using steel or electrical tape (see GWPD 1 and GWPD 3-Cunningham and Schalk, 2011). If the well does not have an access point for measuring water levels, note this fact in the station folder.

- Review seasonal water-level declines that could make the well unsuitable for use as a sampling site.

- Identify nearby wells that could affect the well hydraulics.

- Identify the permanent measuring point and other reference marks; establish them if necessary (see GWPD 3-Cunningham and Schalk, 2011).

\subsubsection{Reconnaissance for Selecting Existing Wells}

Existing wells are typically appealing to project personnel, because they circumvent the cost of drilling new wells. Before selecting existing wells, however, determine whether they are in good condition and meet the objectives of the project.

\section{- Consider the following when evaluating existing wells-}

- Check that the well structure is intact:

- Check depth to bottom and compare it to the original construction information. A decrease in depth can indicate that the well screen or casing is filling with loose material, breached, or collapsing (Lapham and others, 1997). If a problem is suspected, borehole caliper or downhole camera logs can be used to identify the affected depth interval(s).

- Check for hydraulic connection between the well and aquifer. A rough check is performed by removing one casing volume of water (avoid drawing water from below the top of the screened interval) and recording the time for the water level to recover its original position. A long recovery time may indicate a poor hydraulic connection, possibly due to plugging or deterioration of a well. When practical, confirm that the connection between the well screen and the aquifer(s) is sound by using aquifer slug tests, depth-to-bottom measurements, borehole caliper tests, downhole video logs, and so forth. This may be prohibitive in wells with existing pumps, at which a single well pump test may suffice.

- Check that the yield of water is adequate for sampling; typically, a minimum of 0.25 gallons (approximately 1 liter) per minute is adequate. Run the pump and monitor drawdown to determine if the well has sufficient yield to avoid excessive drawdown and expose the pump or the well screen. Monitoring wells many need to be redeveloped before sampling.

- The surface seal of an existing USGS monitoring well should be intact and the well should be capped. A concrete pad should surround the well and should be repaired if it is cracked or separated from the outer casing. A tight-fitting well cap should include a small ventilation hole for an above-grade finished well, and a lock to avoid vandalism. For a below-grade (flushmount) finished well, the cap needs to be water tight to prevent drainage of water from the surface into the well.

- When possible, verify the depths to the top and bottom of screened intervals and that the lengths of the screened or open intervals are appropriate for the study objectives.

- Review available records such as drillers' logs and results of previous sample analyses to verify that wells meet study objectives. Identify hydrogeologic units, and include the depth and thickness of the aquifers that contribute water to the well.

- Confirm that well-construction materials are compatible with target analytes and will not leach or sorb them. The pump, casing materials, and tubing should not affect the concentrations of target analytes. If packers are used, their materials must be compatible with target analytes. Freshly glued polyvinyl chloride (PVC) fittings, rusting or punctured casing, a poor surface seal, and so forth, may contribute to sample contamination.

- Ideally, each well has only one screened (or open) interval, but packers can be used to isolate the depth interval of interest. Be aware that packers might not completely isolate the zones of interest in unconsolidated or highly fractured rock. 
- Confirm that borehole or casing/screen diameter is adequate to accommodate the sampling equipment.

- Determine whether a portable pump or bailer will be required and, if so, what type and diameter are needed.

- If the well has a pump, determine-

- Whether it needs to be removed from the well before sampling, or whether it can be used for sampling. Obtain owner permission to remove the pump to minimize liability for damage to the pump or well.

- Whether the flow rate can be controlled, or whether a hose-and-valve system is needed.

- Whether there is oil floating on top of the water column (if the pump is oil-lubricated).

- Whether the well plumbing has an existing access point near the well head prior to holding tanks and treatment, and whether it is necessary to install a hose bib.

- Whether the well has a water-lubricated turbine pump rather than oil-lubricated turbine pump, as found in most modern supply wells.

- Avoid suction-lift, jet, or gas-contact pumps when collecting samples for determination of analytes that are volatile or otherwise are affected by pressure changes or exposure to oxygen/air.

- Identify the optimal pumping rate to ensure adequate purging of the well without entrainment of air due to excessive drawdown.

- If a well has a holding tank or chemical-treatment system, determine whether there is an access point for the raw water before it enters the tank or system. If downhole treatment is used, verify that it can be turned off prior to sampling.

- Verify that the top of the screened (or open) interval is several feet below the typical annual lowest water level, to reduce the chance of the well becoming dry and to avoid sampling water from above the saturated zone.

- Verify that the filter pack is of a reasonable length relative to (not too much longer than) the screened (or open) interval, to avoid sampling water from outside the depth interval of interest.

- Determine the type of equipment and samplecollection methods that will be needed to sample each well. Note any potential difficulties that may be anticipated with the intended equipment. Modify the sampling plan if necessary.
- Decide where to store or route purge water away from the well to prevent muddy or slippery conditions, erosion near the well head, and damage to the property to which you were granted access. If purge water is contaminated, plan for proper disposal.

\subsection{Preparation for Water-Quality Record Keeping}

Field personnel, project managers, and database managers are responsible for establishing and maintaining electronic and (or) paper data records and ensuring their accuracy and completeness. Planning for data management starts before water-quality samples are collected. All original records of data and supporting documents are required to be reviewed and archived so that the information is in an acceptable format for public record and is available for future access (USGS Manual, chapter 502.8-U.S. Geological Survey, 2017b; Water Resources Division Memorandum 92.59-U.S. Geological Survey, 1992). Accordingly, project work plans must include time and resources to work, review, and publish data. Record keeping for water-quality data includes establishing and verifying site information in GWSI, SIMS, and station folders, entering sample information and field data in NWIS, and verifying and archiving data and metadata according to the project data-management plan. This section provides an overview of preparation to collect and manage water-quality data. This section is targeted to USGS policies and procedures for water-quality data collection.

All original records of data and supporting documents are required to be reviewed and archived so that the information is in an acceptable format for public record and is available for future access.

Original records are defined as those data, metadata, and other information that are initially recorded in the field or laboratory. Hubbard (1992) provided clear descriptions of most forms of raw data to be preserved, including data from automated monitoring, field notes, equipment logs, laboratory analyses, and quality assurance. Regardless of whether the original records are paper or electronic, they must be archived and meet disposition requirements and schedules as specified in USGS Manual Records Disposition Schedules (U.S. Geological Survey, 2018b) and Office of Water Quality Policy Memorandum 2016.09 (U.S. Geological Survey, 2016b). It is critical to the reliability of USGS water-quality data and metadata that records are preserved as collected or received according to specified schedules of disposition.

Data that are collected and (or) analyzed by partner agencies (in total or in part) and stored in NWIS are referred to as "furnished records." All furnished records that are entered into NWIS must be comparable in accuracy and collection 
protocols to data collected by the USGS, must be quality assured by the USGS to ensure their accuracy, must be identified as furnished records with the identity of the agency that furnished them ("Collecting Agency" in the Sample Header information, and (or) "Analyzing Agency" in the Sample Result information), and must contribute useful information about the water resources of the Nation (Office of Water Quality Policy Memorandum 2016.08-U.S. Geological Survey, 2016c).

Planning for data management begins before water-quality samples are collected. Project work plans must include time and resources to review and publish data.

\subsection{National Water Information System (NWIS) Files}

All water-resources data produced through USGS WMA activities, including monitoring, investigations, and research, and that fit the formatting requirements of NWIS should be stored in NWIS (USGS Office of Water Quality Technical Memorandum 2008.05-U.S. Geological Survey, 2008a). Basic information on utilizing NWIS for processing waterquality data is presented in this chapter of the NFM, and more detailed documentation is provided in the USGS NWIS Water-Quality User's Manual (accessed September 11, 2017, at http://nwis.usgs.gov/nwisdocs5_2/qw/QW.user.book.html, internal USGS access only).

Station information for surface-water and groundwater sites is stored in the GWSI database in NWIS and is geographically referenced to individual SITEFILE records. SITEFILE records store information on location and site characteristics for each USGS monitoring station. Results of discrete (noncontinuous) chemical analyses are stored in the QWDATA subsystem of NWIS. QWDATA contains records for waterquality samples with results of field measurements, such as discrete water-level and physical field parameters, laboratory analytical results, and metadata associated with each sample. Each sample record in QWDATA is referenced to a unique SITEFILE record in GWSI. Records of continuous water-level and water-quality data are stored in the NWIS Time Series (NWIS-TS) system and also are referenced to unique SITEFILE records.

All water-resources data produced through USGS WMA activities, including monitoring, investigations, and research, and that fit the formatting requirements of NWIS should be stored in NWIS.

Water-quality data that are entered into NWIS are initially coded as provisional and are uploaded regularly to NWISWeb (https://waterdata.usgs.gov/nwis), which is the public portal to NWIS water-resources data. Provisional is a temporary status for data that must be reviewed and updated in a timely manner to a status of either approved and publicly available, or internal only (USGS Manual, chapter 502.4-U.S. Geological Survey, 2016a). The process of Continuous Records Processing (CRP) is used to manage continuous water-quality data. Timelines for record approval for continuous records are affected by the complexity and logistics of each time-series data type at each water-quality monitoring station and are assigned a category with a specified timeframe for CRP (Office of Water Quality Technical Memorandum 2017.02-U.S. Geological Survey, 2017a). Workflow and policies for CRP using Aquarius software and the NWIS Time Series (NWIS-TS) database are provided in Office of Water Quality Technical Memorandum 2017.07 (U.S. Geological Survey, 2017d).

Review and approval of discrete water-quality data is subject to the timing of receipt of analytical results from laboratories, but should be completed on a regular schedule. Once discrete data are reviewed and approved, Data-Quality Indicator (DQI) codes must be reset to indicate that the data are reviewed and no longer provisional.

The timeframe for review and approval of all water-quality records is documented in a project data-management plan. Access to data that need further review beyond the time limits for CRP and data approval should be restricted, such that those data are not publicly available.

\subsubsection{Establishing a New Site in NWIS}

Field personnel are responsible for providing the necessary information to establish SITEFILE records for each new sampling site and verifying that existing site information is correct. Updates to the SITEFILE should be made promptly. New sites are established prior to fieldwork or immediately following field reconnaissance. The minimum information required for establishing SITEFILE records in GWSI and sample records in QWDATA is summarized for surface water (table 1-2) and groundwater (table 1-3). Individual studies and USGS WSC offices may have additional datastorage requirements.

A USGS site schedule, form 9-1904-A (appendix A) must be completed in order to establish a new site in NWIS. The site-schedule form can be produced from the USGS field computer application Management and Population of Sites (MAPS). Form 9-1904-A is submitted to the local WSC surface-water or groundwater specialist, who will assign a unique site-identification number and official name, and then to the local WSC NWIS database administrator (DBA), who will create a new SITEFILE in GWSI. Numbering for surface-water sites usually follows USGS protocols, by which a unique downstream order number is assigned to each station. Identification numbers for groundwater sites (and some surface-water stations) have a 15-digit latitude/longitude format ending with a 2-digit sequence number. All new site entries must be reviewed by the local WSC discipline specialists and NWIS DBAs to avoid duplicating station numbers or assigning incorrect downstream order numbers. If a station is established outside the jurisdiction of the WSC conducting 
the study, then the SITEFILE should be established with the WSC that has oversight for that location. Consult the data-management plan for your WSC for specific and more detailed guidance.

If the new station will be monitored for continuousrecord data that will be transmitted to NWIS, the NWIS DBA will set up the web display in NWIS-TS once the SITEFILE record has been created. Additional information, such as instrument types, logging intervals, and so forth, will be needed for the website. Reserve time at the beginning of the project to meet with the WSC specialists and DBAs and establish station information in NWIS.

In order to establish a new USGS station (surface-water and groundwater stations), accurate latitude and longitude must be determined to locate the station on a topographic map. GPS is the preferred method for determining coordinates for latitude/longitude.
Reserve time at the beginning of the project to meet with the WSC specialists and DBAs and establish station information in NWIS.

\subsubsection{Documentation of an Existing SITEFILE in NWIS}

For existing USGS stations, project personnel retrieve and review all available information for the station in NWIS and any paper files that may be archived at the WSC. This information is then verified during field visits. SITEFILES in NWIS are updated with current and newly available information.

Table 1-2. Minimum information required for electronic storage of a surface-water SITEFILE record in the GWSI, and surface-waterquality data in OWDATA of the USGS NWIS.

[USGS, U.S. Geological Survey; NWIS, National Water Information System; GWSI, Groundwater Site Inventory database; QWDATA, Quality of Water database]

\begin{tabular}{|c|c|c|}
\hline \multicolumn{3}{|c|}{ Required information for creation of a surface-water site record in the GWSI ${ }^{1}$} \\
\hline Data description & $\begin{array}{l}\text { Component (C) number for entry } \\
\text { into the GWSI }\end{array}$ & Examples of data entry ${ }^{2}$ \\
\hline $\begin{array}{l}\text { Site-identification number (using upstream/downstream } \\
\text { order) }\end{array}$ & $\mathrm{C} 1$ & 11530500 \\
\hline Latitude (dddmmss.s) & C9 & 413040.2 \\
\hline Longitude (dddmmss.s) & $\mathrm{C} 10$ & 1235842.7 \\
\hline Latitude/longitude accuracy & $\mathrm{C} 11$ & $\mathrm{~S}$ (seconds) \\
\hline Latitude/longitude method & $\mathrm{C} 35$ & G (GPS) \\
\hline Daylight Saving Time flag & C814 & Y (Yes) \\
\hline Country & $\mathrm{C} 41$ & US \\
\hline State & $\mathrm{C} 7$ & 06 (California) \\
\hline County & $\mathrm{C} 8$ & 015 (Del Norte) \\
\hline District (Water Science Center/user) & C6 & 06 (California) \\
\hline Agency use of site & $\mathrm{C} 803$ & A (Active) \\
\hline Site type & $\mathrm{C} 802$ & ST (Stream) \\
\hline
\end{tabular}


Table 1-2. Minimum information required for electronic storage of a surface-water SITEFILE record in the GWSI, and surface-waterquality data in OWDATA of the USGS NWIS. - Continued

[USGS, U.S. Geological Survey; NWIS, National Water Information System; GWSI, Groundwater Site Inventory database; QWDATA, Quality of Water database]

\begin{tabular}{|c|c|c|}
\hline \multicolumn{3}{|c|}{ Required and recommended information for storage of quality of surface-water data in OWDATA ${ }^{3}$} \\
\hline Agency code & AGNCY & USGS \\
\hline Station number & STAID & 11530500 \\
\hline Begin date (YYYYMMDD) & BDATE & 20150909 \\
\hline End date (YYYYMMDD) & EDATE & Applicable only for composite sample \\
\hline End time (24-hour clock time, HHMM) & ETIME & Applicable only for composite sample \\
\hline Time datum & TMDTM & PDT \\
\hline Station medium & MEDIM & WS (surface water) \\
\hline Hydrologic event & EVENT & 9 (routine sample) \\
\hline Hydrologic condition & HSTAT & 9 (stable stage) \\
\hline Analysis status & ASTAT & U (unrestricted) \\
\hline Type of quality-control sample collected & 99111 & 10 (blank) \\
\hline Sampling method & 82398 & 10 (equal-width increment) \\
\hline Sampler type & 84164 & 3051 (US DH-95 Teflon bottle) \\
\hline Instantaneous discharge & 00061 & In cubic feet per second \\
\hline
\end{tabular}

\footnotetext{
${ }^{1}$ Modified from Groundwater Site Inventory Schedule, Form 9-1904-A (accessed September 11, 2017, at http://nwis.usgs.gov/forms/gwforms.html, internal USGS access only).

${ }^{2}$ Additional values for components and attributes for NWIS SITEFILE entry can be found at http://nwis.usgs.gov/nwisdocs5_2/gw/gwcoding_Sect2-1.pdf (accessed September 11, 2017, internal USGS access only).

${ }^{3}$ Additional codes for QWDATA sample-data entry can be found at http://nwis.usgs.gov/nwisdocs5_2/qw/QW-AppxA.pdf (accessed September 11, 2017, internal USGS access only).
} 
Table 1-3. Minimum information required for electronic storage of a surface-water SITEFILE record in the GWSI, and surface-waterquality data in OWDATA of the USGS NWIS.

[Modified from GWSI Schedule, Form 9-1904-A; USGS, U.S. Geological Survey; NWIS, National Water Information System; GWSI, Groundwater Site Inventory; QWDATA, Quality of Water database]

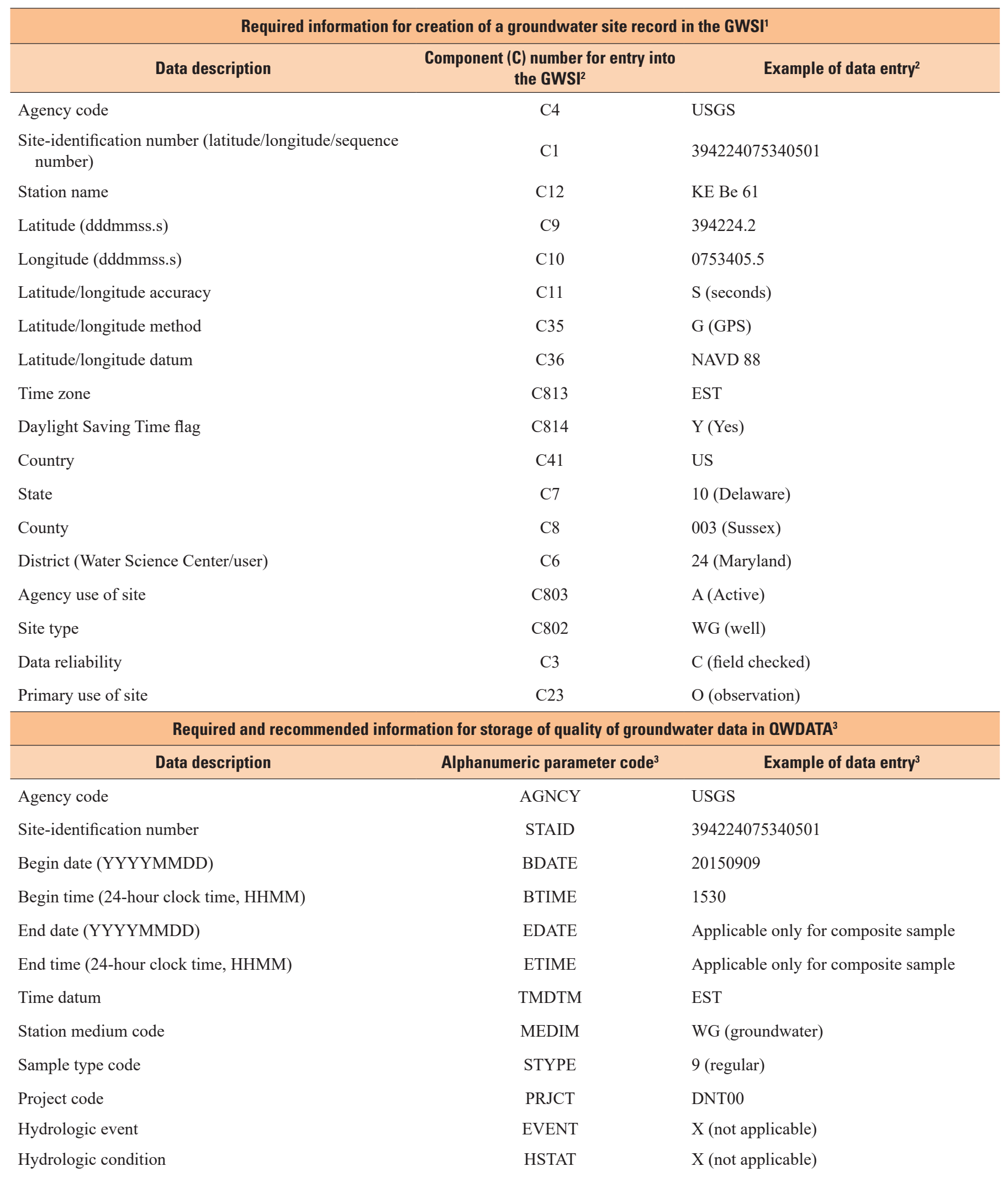


Table 1-3. Minimum information required for electronic storage of a surface-water SITEFILE record in the GWSI, and surface-waterquality data in OWDATA of the USGS NWIS.-Continued

[Modified from GWSI Schedule, Form 9-1904-A; USGS, U.S. Geological Survey; NWIS, National Water Information System; GWSI, Groundwater Site Inventory; QWDATA, Quality of Water database]

\begin{tabular}{lcc}
\hline \multicolumn{1}{c}{ Required and recommended information for storage of quality of groundwater data in OWDATA $^{3}$ - Continued } \\
\hline \multicolumn{1}{c}{ Data description } & Alphanumeric parameter code ${ }^{3}$ & \multicolumn{1}{c}{ Example of data entry $^{\mathbf{3}}$} \\
\hline Type of quality-control sample collected & 99111 & 30 (Replicate) \\
Depth to water level & 72019 & In feet below land surface \\
Sampling depth & 00003 & In feet \\
Flow rate & 00059 & In gallons per minute \\
Sampling method & 82398 & 4030 (Suction pump) \\
Sampler type & 84164 & 4030 (Suction pump) \\
\hline
\end{tabular}

${ }^{1}$ Modified from Groundwater Site Inventory Schedule, Form 9-1904-A (accessed September 11, 2017, at http://nwis.usgs.gov/forms/gwforms.html, internal USGS access only).

${ }^{2}$ Additional values for components and attributes for GWSI SITEFILE entry can be found at http://nwis.usgs.gov/nwisdocs5_2/gw/gwcoding_Sect2-1.pdf (accessed September 11, 2017, internal USGS access only).

${ }^{3}$ Additional codes for QWDATA sample-data entry can be found at http://nwis.usgs.gov/nwisdocs5_2/qw/QW-AppxA.pdf (accessed September 11, 2017, internal USGS access only).

\subsection{Site Information Management System (SIMS)}

The USGS SIMS is a storage framework for supporting information and metadata for USGS monitoring stations. The SIMS application is capable of storing station descriptions, manuscripts, annual station analyses, real-time data-collection platform (DCP) information, sitehazard analyses (SHA), traffic-control plans, photographs, and site-cooperator agreements. SIMS is integrated with NWIS and NWISWeb to provide manuscript and water-year summaries on the web. SIMS also is linked to the records management system (RMS) to provide tools for CRP. SIMS can be accessed at http://sims.water.usgs.gov/SIMS/ (accessed September 11, 2017, internal USGS access only). It is strongly recommended that all continuous USGS monitoring stations be entered in SIMS and RMS with current information.

\subsection{Forms for Field Notes, Analytical Services, and Chain of Custody}

Standard field forms for collecting water-quality data are available at https://water.usgs.gov/usgs/owq/Forms.html (accessed September 11, 2017, internal USGS access only). These forms are customizable for individual project needs, and provide a good checklist for all of the information that should be recorded on each field trip. Analytical service request forms (ASRs) are specific for each laboratory and provide a useful checklist for information that the laboratory will need to complete its analyses. The USGS National Water-Quality Laboratory (NWQL) requires the use of the latest version of their ASR (USGS Office of Water Quality Technical Memorandum 2015.02-U.S. Geological Survey, 2015). If chain-of-custody (COC) forms will be required for a project, review laboratory $\mathrm{COC}$ procedures and prepare the appropriate $\mathrm{COC}$ forms that will be needed.

\subsubsection{Personal Computer Field Form (PCFF)}

The PCFF is a Windows-based software package developed by the USGS to record and upload water-quality sample data electronically to QWDATA in USGS NWIS (internal USGS access only). PCFF is configured with project-specific coding information that is organized into tables for efficient and accurate data entry in the field. Before going to the field to collect water-quality samples, configure PCFF with project-specific information: site-identification numbers and station names; account numbers; laboratory schedules to request; preferred parameter and method codes; meter serial numbers; and lot numbers for calibration standards, microbiological media, reference solutions, sample preservatives, and filters. USGS-approved algorithms allow for automated computation of alkalinity, microbiology, and other parameters once required fields are populated. The

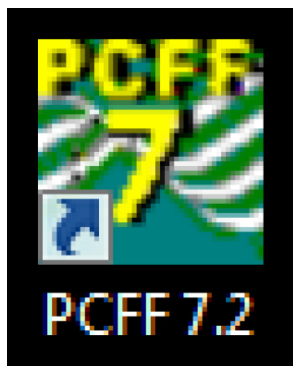


software can generate all required field and ASR forms, and batch output files that can be loaded automatically or manually into QWDATA. Advantages of PCFF include time savings, fewer transcription errors with one-time data entry, and electronic archiving of water-quality records.

\subsection{The Project Work Plan}

The field-trip itinerary should be planned and coordinated with the project team in advance of fieldwork. The project work plan outlines routine field-trip and data-handling procedures, policies, maintenance, and safety practices. Expectations for completion of data collection and processing are clearly defined and communicated to the entire project team.

Project work plans are required by USGS Fundamental Science Practices (USGS Manual, chapter 502.2-U.S. Geological Survey, 2011). They are part of the careful planning to document procedures and define data-quality requirements necessary to achieve the goals of the project. The data-quality requirements determine the appropriate sampling design for collection of data that are representative of the aquatic system being studied, analytical requirements such as reporting limits and precision, and the types and numbers of environmental and quality-control samples to be collected. The project work plan should be reviewed and approved by the WSC water-quality specialist and the project supervisor. A subset of the project work plan is a set of written standard operating procedures (SOPs) that are referred to during field activities.

"The project work plan documents the timeline for the study, lists the discrete tasks that need to be completed to accomplish the objectives, and describes the relationship of discrete tasks to one another and the methods to be used (how they can be explained and defended, including exploring differences in performance, comparability of results, and so on). A project work plan also documents the budget and staffing for the study, anticipated or planned information products (including the recommended review and approval process for these products), and the process for managing and archiving scientific records."

-Fundamental Science Practices (USGS Manual, chapter 502.2-U.S. Geological Survey, 2011)

Among the many components of a USGS project work plan are (1) scope and timeline with budget; (2) SOPs for all planned data-collection activities and technical methods that will be implemented; (3) QAP to assess and document the quality of the data; (4) Data-Management Plan for collection, review, and approval of the data products; and (5) plans for analyzing and publishing the data. The timeline should include major project elements with timing for availability of staff and equipment needs, and milestones to review progress and make timely course corrections during the study. The project budget must include adequate salary and resources allocated to complete all steps. All elements of the work plan are shared with the entire project team so that everyone is working toward common goals.

\subsection{Standard Operating Procedures (SOPs)}

Standard operating procedures or SOPs are a required element of the project work plan under Fundamental Science Practices (USGS Manual, chapter 502.2-U.S. Geological Survey, 2011). SOPs provide detailed instructions for the methods and approaches that the field team will use to conduct the technical elements of the project.

\section{- Project SOPs include-}

- Detailed methods for collecting and processing water-quality samples and making field measurements. The USGS NFM provides many standard methods that can be referenced in the project SOPs.

- Instructions for locations, frequency, and types of samples to be collected.

- Lists of the laboratories and analytical tests that will be used.

- Instructions for all procedures that will be conducted by field staff. If samples will be shipped to laboratories, the SOP provides instructions for sample processing and shipping.

- Safety instructions for each procedure in the form of a Job Hazard Analysis.

\subsection{Quality-Assurance Plan (QAP)}

A quality-assurance plan (QAP) provides the design for quality assurance (QA) and quality-control (QC) sampling to document bias and variability in environmental data. The QAP provides a means to continually maintain and document data quality throughout the entirety of the project. Each WSC is required to have a QAP for water-quality activities in the center, and projects are encouraged to develop a QAP that specifically addresses individual project needs (Office of Water Quality Technical Memorandum 2014.02-U.S. Geological Survey, 2014a). The project QAP can reference the WSC QAP for all standard protocols; any QA/QC activities that are not covered by or vary from the WSC QAP must be adequately covered in a project QAP. A project-specific QAP may be required for certain projects or cooperators.

\section{- The project quality-assurance plan includes-}

- Determination of the QC-sample types, the frequency of QC-sample collection, their intended purpose over the life of the project, and a plan for 
reviewing QC results. Types of quality-control samples include blanks, replicates, spikes, and standard reference materials.

- Blanks are samples prepared from certified targetanalyte-free water that is intended to be free of measurable concentrations of the constituents that will be determined. Blanks are prepared following the same steps and procedures of environmental sample collection and (or) analysis and are used to estimate bias in the data during these procedures. Blanks are an essential part of all water-quality data-collection activities. Blanks should be collected before the onset of environmental sampling to identify potential bias issues early in the project, and then on a regular schedule during field sampling. Blanks can be collected to answer topical questions and isolate bias issues for individual pieces of equipment and steps in sample processing, or they can encompass the entire sampling and analysis process (Mueller and others, 2015). Water that is used for blanks must be matched to the analytes being measured and have a verified analysis to ensure that it does not itself bias the analysis. USGS One Stop ${ }^{2}$ provides inorganic-free blank water (IBW) for analysis for major ions, nutrients, and trace metals, organic-free pesticidegrade blank water (OBW) that is certified for analysis for pesticides and other trace organic compounds, and volatile pesticide-grade blank water (VBW) that is OBW that has been purged with pure nitrogen and certified for analysis for trace volatile organic compounds.

- Replicates of environmental samples are collected to estimate natural variability in the aquatic system as well as variability in sample collection, sample processing, and chemical analysis. Replicates are important for quantifying the precision of measurements of environmental water quality.

- Other types of QC samples such as spikes and standard reference materials should be considered to evaluate issues such as matrix effects in the analyses and recovery efficiencies of analytical methods.

- Laboratories that are proposed for the analysis of water-quality samples must be evaluated to ensure adequate data quality. All laboratories, including the USGS NWQL, must be evaluated to confirm that the analyses provided will meet the data-quality objectives of the project. USGS project personnel must complete the USGS Laboratory Evaluation Program (LEP) process for each laboratory used (Office of Water Quality Technical Memorandum 2014.01U.S. Geological Survey, 2014c).

Mueller and others (2015) provided comprehensive guidance for collecting and interpreting QC data. USGS Fundamental Science Practices state that USGS data are to be collected by using methods that are documented to describe the processes used and the QA procedures applied (USGS Manual, chapter 502.2, Fundamental Science Practices-U.S. Geological Survey, 2011).

USGS Fundamental Science Practices state that USGS data are to be collected by using methods that are documented to describe the processes used and the qualityassurance procedures applied.

-Fundamental Science Practices (USGS Manual, chapter 502.2-U.S. Geological Survey, 2011)

\subsection{Project Data-Management Plan}

The work plan for every USGS data-collection project must include planning and resources for data management. Project data-management plans are required by USGS Fundamental Science Practices (USGS Manual, chapter 502.6-U.S. Geological Survey, 2017c). A data-management plan describes standards and intended actions for acquiring, processing, analyzing, preserving, publishing/sharing, describing, managing the quality of, backing up, and securing the data holdings. The USGS provides support for data-management planning at https://www.usgs.gov/datamanagement/plan.php (accessed June 9, 2018). The data-management plan, like the work plan, is required by USGS Fundamental Science Practices and should be updated at key milestones during the research and monitoring phases of a project to reflect changes in the project activities and objectives. USGS projects should review and approve water-quality records on a schedule that is as short as practicable after data have been entered into NWIS (see Office of Water Quality Technical Memorandum 2012.03-U.S. Geological Survey, 2012; and Water Resources Division Policy Memorandum 2010.02-U.S. Geological Survey, 2010a).

"The USGS must provide the best data of known quality to the public as soon after collection as possible." -Office of Water Quality Technical Memorandum 2012.03 (U.S. Geological Survey, 2012)

${ }^{2}$ Equipment and supplies that are tested and quality assured are available to USGS field studies from the National Field Supply Service (NFSS) and the Hydrologic Instrumentation Facility (HIF), and are sold through the USGS One Stop ordering system (accessed September 11, 2017, at https://1stop.usgs.gov/, internal USGS access only). 


\subsection{Final Preparation for Field Sampling}

Field personnel must assure that all necessary supplies and resources are prepared before fieldwork commences. Review all requirements for water-quality sampling and data quality and complete detailed field-trip preparations prior to sample collection. This process includes checking that equipment is in good working order and available during the time period for the planned fieldwork, that all reagents and standards are available and fresh (not beyond their expiration date), and that all the necessary forms and information are assembled. The physical and chemical limitations of each piece of equipment should be reviewed with respect to data-collection objectives and data-quality requirements. The operational range of the sampling equipment to be used should be verified and tested, ahead of time if possible. Electronic versions of water-quality field forms can be downloaded at https://water.usgs.gov/usgs/owq/Forms.html (accessed September 11, 2017, internal USGS access only). Some of the steps to consider for final preparations for fieldwork follow (table 1-4):

Review all requirements for water-quality sampling and data quality and complete detailed field-trip preparations prior to sample collection.

Table 1-4. Checklist for preparation to conduct field sampling.

[USDA, U.S. Department of Agriculture; PCFF, personal computing field form]

\begin{tabular}{|c|c|}
\hline \multicolumn{2}{|r|}{ Project readiness } \\
\hline $\begin{array}{l}\text { Project calendar and } \\
\text { general planning }\end{array}$ & $\begin{array}{l}\text { - Review project work plan } \\
\text { - Prepare calendar of planned field trips with sampling dates, members of field team(s), equipment and } \\
\text { vehicle(s), and types of samples to be collected. } \\
\text { - Prepare sampling log with planned environmental and quality-control samples. }\end{array}$ \\
\hline $\begin{array}{l}\text { Safety equipment and } \\
\quad \text { information } \\
\text { (see Section } 5.1)\end{array}$ & $\begin{array}{l}\text { - Review the Job Hazard Analysis (JHA) for each procedure and the station hazard analysis (SHA) for each site } \\
\text { (see example in table 1-5). } \\
\text { - Prepare traffic safety plan (see example in figure 1-1). } \\
\text { - Ensure that all field personnel have completed required safety training. } \\
\text { - Check field vehicle for maintenance and safety equipment. } \\
\text { - Secure all necessary safety equipment: gloves, eyewear, personal flotation devices, traffic cones, and so forth. } \\
\text { - Assemble emergency contact information in vehicles and station folders. Give copies to supervisor in case of } \\
\text { emergency. }\end{array}$ \\
\hline Contacts & $\begin{array}{l}\text { - Provide trip details and call-in information to supervisor. } \\
\text { - Share contact information for each member with the whole project team. }\end{array}$ \\
\hline \multicolumn{2}{|r|}{ Site preparation } \\
\hline $\begin{array}{l}\text { Permissions for site } \\
\text { access }\end{array}$ & - Place copies of permission forms in field vehicle(s); store original with project files. \\
\hline $\begin{array}{l}\text { Creating or updating } \\
\text { station folders }\end{array}$ & - Document all information and logistics for sites and sampling (tables 1-6 and 1-7). \\
\hline Travel arrangements & $\begin{array}{l}\text { - Assemble maps. } \\
\text { - Print hotel tax-exempt forms. } \\
\text { - Determine where to buy ice, sample-shipping locations, hardware stores, and so forth. }\end{array}$ \\
\hline
\end{tabular}


Table 1-4. Checklist for preparation to conduct field sampling.-Continued

[USDA, U.S. Department of Agriculture; PCFF, personal computing field form]

\section{Equipment and supplies}

- Prepare checklists of equipment and supplies for each field site.

- Create a list of items to be ordered.

Equipment needs

- Verify that all equipment is tested and working to specifications.

- Check batteries, including a load test for 12-volt lead/acid batteries.

- Bring spare batteries.

- Calibrate meters and multiparameter sondes prior to sample trip to test correct operation and function.

- Ensure vehicle maintenance is up to date. Check wiper fluid, coolant, fuel, tire pressure, battery, lights, and so forth.

- Ensure safety equipment is in good condition in vehicle, including-first aid kit, fire extinguisher, traffic cones and flags, and emergency contact information.

- Ensure all equipment is safely secured in vehicles.

- Have traffic-control plans (paper copy or electronic version) available for each site.

- Assemble supplies - gloves, sample bottles, filters, plastic storage bags, standards, blank water, preservatives, spike kits, and so forth.

- Assemble supplies for cleaning in the field - washing solution, tap rinse, deionized water (DIW).

Supplies and consumables

- Check expiration dates of consumables.

- Create a list of supplies to be ordered.

- Print copies of Safety Data Sheets (SDS) for all chemicals needed for fieldwork.

- Assemble coolers with ice, plastic trash bags for liners, and return shipping labels.

\section{Sampling preparation}

- Prepare field forms, analytical services requests (ASRs, Office of Water Quality Technical Memorandum 2015.02-U.S. Geological Survey, 2015), chain-of-custody forms (if needed), and USDA restricted soils forms (if needed). Some of the information on these forms can be filled in before the field trip.

- Bring all of the information needed for coding on field forms - project account numbers, medium codes, analytical schedules and lab codes, bottle types, preservation requirements, and shipping instructions. Verify that all of this information is correct.

- Populate PCFF with project information.

- Prepare shipping labels and return labels for shipping containers.

- Prepare paperwork for quality-control samples.

- Prepare a bottle set for each sample with all of the bottles needed for planned laboratory schedules. Store each

Bottle sets bottle set in a clean zip-top resealable plastic bag that will be used to ship the sample.

- Prepare bottle labels with site information, sample types, medium codes, and so forth.

\subsection{Safety Preparedness}

Potential safety hazards are unique to each site, each project, and every procedure. Preparation for potential hazards is critical for safe and successful completion of sampling objectives. Safety and health policy and training requirements for USGS employees are provided in the USGS "Occupational Safety and Health Program Requirements Handbook” (USGS Manual, chapter SM 445-2-H-U.S. Geological Survey, variously dated) and the USGS handbook, "Safety and Health for Field Operations" (U.S. Geological Survey, 2014b). USGS has a strong training program, with special guidance for people who are exposed to hazards in the field. Each WSC has a written plan regarding health and safety that covers USGS employees who may encounter hazards while conducting field and lab work. USGS employees are required to complete assigned safety training prior to conducting their work. 


\subsubsection{Job Hazard Analysis (JHA)}

A JHA is a technique that focuses on job tasks as a means to identify hazards before they occur. Forms used to complete a JHA are provided in the USGS handbook "Safety and Health for Field Operations" (U.S. Geological Survey, 2014b). A JHA involves all employees on the project in reviewing the field and (or) laboratory procedures, identifying uncontrolled hazards and any historical accidents, and then eliminating or reducing the risks with corrective and preventive procedures. Periodically during the project, the project chief and supervisor should revisit the JHA to verify that field personnel are following safety guidelines, identify new potential hazards, and make corrections where needed. The JHA can be created in SIMS.

A Job Hazard Analysis, or JHA, is a technique that focuses on job tasks as a means to identify hazards before they occur.

-USGS Safety and Health for Field Operations handbook (U.S. Geological Survey, 2014b)
An example of a JHA for collecting water-quality samples in the field is provided below (table 1-5).

\subsubsection{Site Hazard Analysis (SHA)}

Traffic safety around the site must be documented carefully to ensure that all field personnel who visit the site are aware of hazards and understand the requirements for traffic navigation, safe parking, and sampling routines. An example of a traffic-control safety plan is shown in figure 1-1. The traffic-control safety plan should be stored in SIMS as well as printed and stored in the field vehicle and (or) gage house or otherwise electronically accessible to field staff conducting field activities. Other site hazards that should be documented may include guard dogs, wild animals, buried electrical wiring, and railroad crossings. Be sure to carry cones and signs for parking, to comply with specific traffic-control safety plans.

"Safety First!" is the motto for all USGS personnel involved in field activities.

Table 1-5. Example-Job Hazard Analysis (JHA) for water-quality measurements in the field.

[Modified from examples of JHAs on internal USGS web pages for water-resource safety; this JHA example is targeted to a particular project and station and would need to be modified for new applications; USGS, U.S. Geological Survey; QW, quality of water; ANSI, American National Standards Institute; PFD, personal flotation device]

\begin{tabular}{|c|c|c|}
\hline \multirow{2}{*}{$\begin{array}{l}\text { Job } \\
\text { Hazard } \\
\text { Analysis }\end{array}$} & $\begin{array}{l}\text { Job description: } \\
\text { Sampling for nutrients } \\
\text { at QW-monitoring } \\
\text { stations }\end{array}$ & $\begin{array}{l}\text { PAGE } 1 \text { of } 1 \\
\begin{array}{l}\text { Organization:___ U.S. Geological Survey_ } \\
\text { Location: }\end{array} \\
\text { New: }\end{array}$ \\
\hline & $\begin{array}{l}\text { Employee/operator: } \\
\text { All employees }\end{array}$ & $\begin{array}{l}\text { Supervisor: } \\
\text { Analysis by: } \\
\text { Certified by: } \\
\text { Date: }\end{array}$ \\
\hline Activity & Potential accidents/hazards & Recommended safe job procedures and protective equipment \\
\hline $\begin{array}{l}\text { 1. Loading and } \\
\text { unloading } \\
\text { equipment }\end{array}$ & Pinching fingers, back strain & $\begin{array}{l}\text { - Stay alert; be aware of hand placement. } \\
\text { - Use caution lifting heavy equipment. Use proper lifting techniques and lift with } \\
\text { legs. }{ }^{1}\end{array}$ \\
\hline
\end{tabular}


Table 1-5. Example-Job Hazard Analysis (JHA) for water-quality measurements in the field.—Continued

[Modified from examples of JHAs on internal USGS web pages for water-resource safety; this JHA example is targeted to a particular project and station and would need to be modified for new applications; USGS, U.S. Geological Survey; QW, quality of water; ANSI, American National Standards Institute; PFD, personal flotation device]

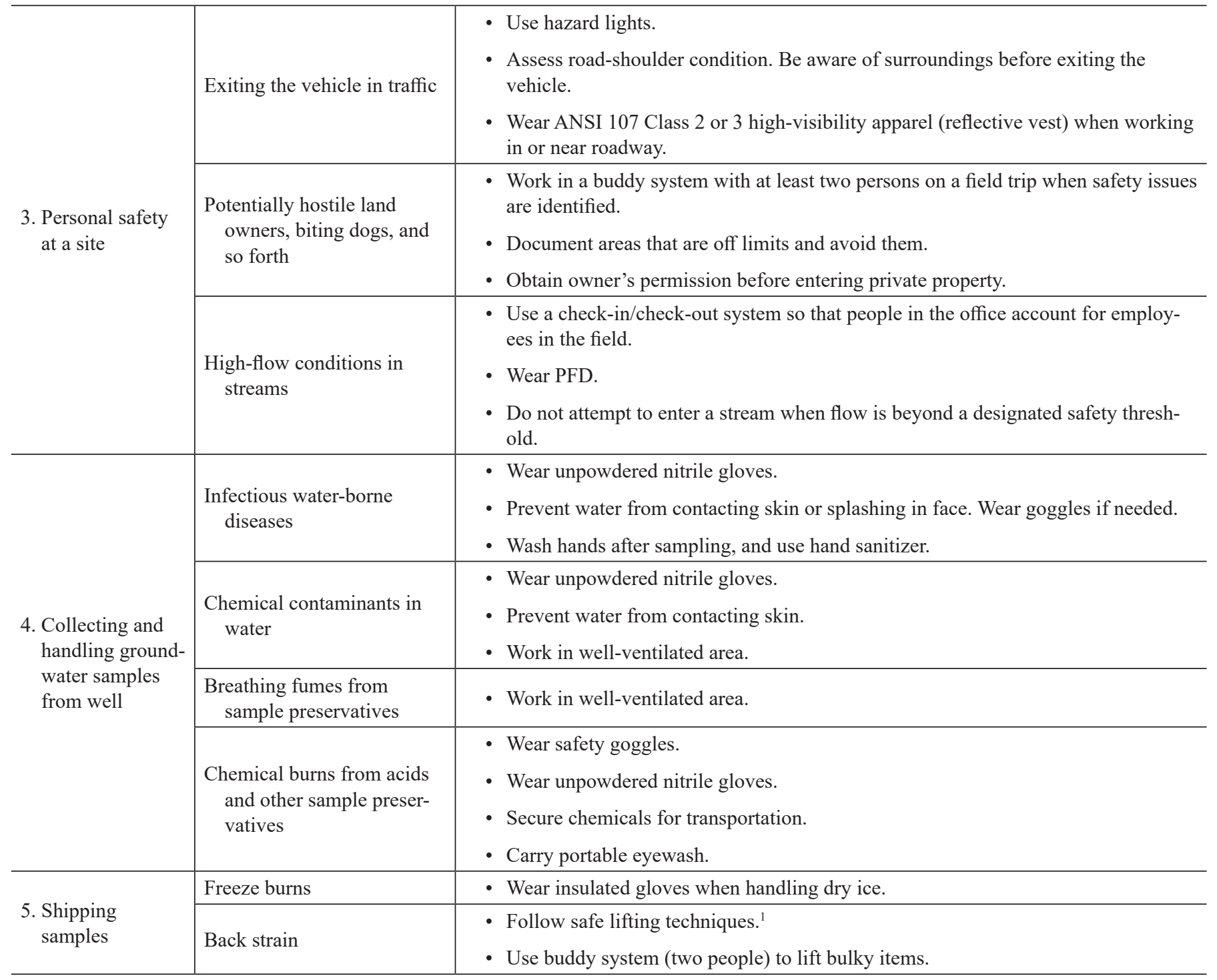

${ }^{1}$ See "Safety and Health for Field Operations" handbook (U.S. Geological Survey, 2014b, p. 108-109) for National Institute for Occupational Safety and Health (NIOSH) recommendations for lifting. 


\section{Typical diagrams for work zones and meaning of symbols}
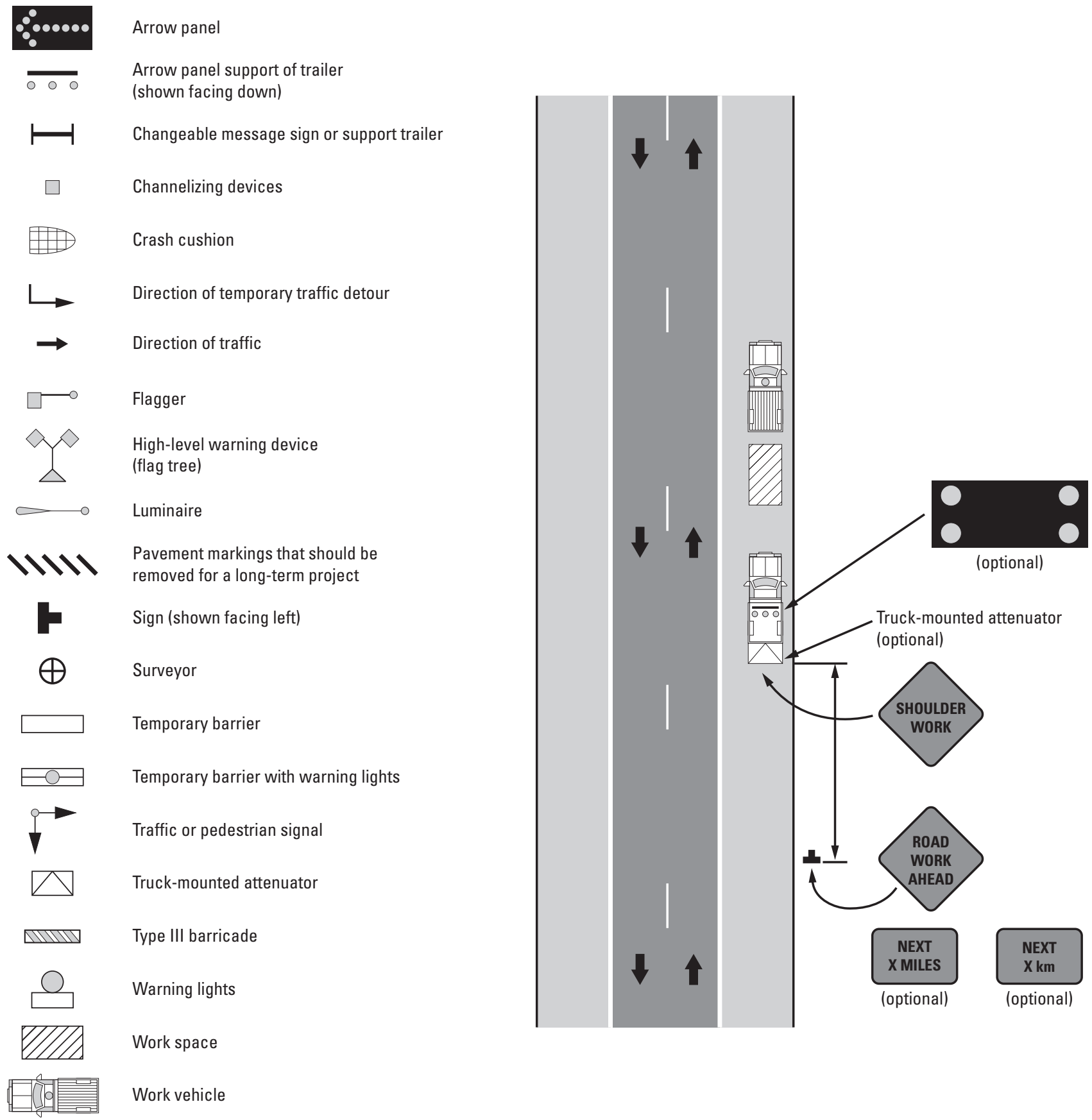

Figure 1-1. Example of a traffic-control safety plan. (Modified from U.S. Geological Survey, 2014b) 


\subsubsection{Safety Training}

Safety training, required for all USGS employees, provides the necessary knowledge and skills to perform potentially hazardous work safely and effectively. Safety requirements and resources for training USGS personnel to safely conduct fieldwork are provided in chapter 14 of the USGS Manual handbook SM 445-2-H (U.S. Geological Survey, 2008c) and the USGS Safety and Health Management web page (internal USGS access only). The WSC Safety Plan will have additional requirements that must be met before personnel are allowed to participate in field activities. USGS personnel should never perform field or laboratory work without completing all required safety and procedural training.

\subsection{Station and Project Files}

Station and project files are the comprehensive supporting information for field trips to USGS monitoring stations, including - station location and description with maps and photographs, historical background information on the site, NWIS site and data entries, guidance for monitoring and sampling at the site, and safety information including a sitehazard analysis and traffic-control safety plan. Information for station and project files is stored in NWIS, SIMS, and electronic or paper project folders. Collectively, the station and project files for a USGS monitoring station are referred to as a "station folder." Previous policies that required field folders or site files to be stored in paper format at field locations are superseded by Office of Water Quality Technical Memorandum 2016.09 (U.S. Geological Survey, 2016b) to accommodate electronic formats. Information that is needed for field monitoring of water quality is organized by station according to WSC and project data-management plans and must be available to trained USGS field personnel to locate sites and safely collect and process water samples. Some emergency information, such as hospital locations, contact information for local law enforcement, and project contacts, should still be kept in hardcopy in field vehicles. Tables 1-6 and 1-7 list the information that should be considered for inclusion in station folders; these lists can be customized for individual data needs. Figure 1-2 ( $A$ and $B$ ) provides examples of a site-location map and a sketch of a field site.

\section{- To prepare location maps and site sketches-}

1. Locate field sites on a USGS 7.5-minute topographic quadrangle map, an aerial photograph, or other source such as a report map (see figure 1-2A, for example) or local development map. These maps are used to locate the sites during subsequent site visits.

2. Determine the latitude and longitude of each site to the nearest second by using a USGS 7.5-minute latitude-longitude scale, a digitizer, or a GPS, and record the latitude and longitude accuracy as 1 second.

3. Prepare a detailed sketch of the site (see example in figure $1-2 B$ ). Orient the site on the sketch map relative to north by using a compass. The sketch map should contain enough detail so that the site can be found again by a person who has never visited it. Distances should be made in feet from permanent landmarks, such as buildings, bridges, culverts, road centerline, and road intersection. Include locations of measuring points at the site.

4. Retain all maps and sketches in the station folder for future reference.

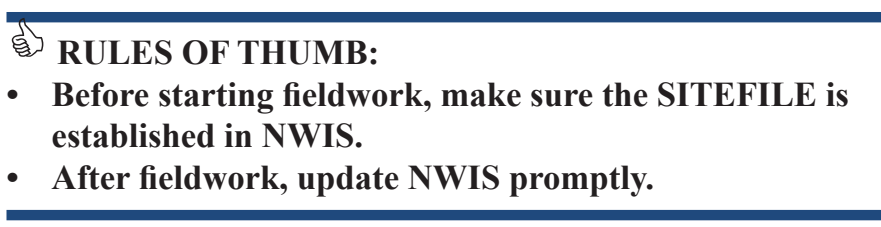

\section{Acknowledgments}

The information in the U.S. Geological Survey (USGS) National Field Manual (NFM) is based on existing manuals, various reference documents, and a broad spectrum of expertise provided by USGS colleagues. Authors of previous versions of NFM chapter A1 were D.B. Radtke, Jacob Gibs, R.T. Iwatsubo, and F.D. Wilde. The persistence and spirit that all of our colleagues brought to the development of a national field manual were invaluable.

The following USGS colleagues provided detailed reviews that improved the technical quality of this report: Windy Brace, Gerolamo Casile, Timothy Oden, and Stanley Skrobialowski. Editorial and production assistance from Marilyn Billone, Sandy Cooper, Elizabeth Good, Cathy Knutson, Katharine Schindler, and Dale Simmons is greatly appreciated. These individuals contributed to the accuracy, quality, and usability of the NFM, and demonstrated much patience as we traversed the difficult task of developing the new format.

Special thanks are extended to Franceska Wilde (USGS), who led the effort for the NFM from its inception until her retirement in 2014; the USGS NFM Steering Committee (Gerolamo Casile, Michael Manning, Cherie Miller, Callie Oblinger, Timothy Oden, Lisa Olsen, Michael Rosen, and Stanley Skrobialowski); Cherie Miller, who led the effort from 2016 to 2018; and Gerolamo Casile, who assumed responsibility for the NFM in 2018. 
Table 1-6. Information to be included in a station folder for surface-water-quality monitoring stations.

[Modified from U.S. Geological Survey, 2006b; SIMS, Site Information Management System; GWSI, Groundwater Site Inventory subsystem software within the USGS National Water Information system (NWIS)]

\section{Site information}

- Station description from SIMS.

- Copy of GWSI form 9-1904-A (appendix A) for each station.

- Location information with maps, directions to site, and site sketch map with reference marks and sampling points (see figure 1-2 [A and B] for examples).

- Datum corrections with record of correction and supporting data.

- Landowner and site-access instructions (for example, "call owner or site operator before arrival, obtain key to unlock security gate"). Copies of agreements for permission to access property and collect samples.

- Photographs of stream segment and vicinity.

- Location of nearest gaging station(s).

- Stream-access locations to measure flow and collect samples.

- Equipment installed at site including controls in the stream.

- Streamflow information-

- Discharge-rating curves or tables.

- Extremes for high- and low-flow conditions.

- Flow-duration curve.

- Cumulative-discharge curves and velocity cross sections at approximately 10-, 50-, and 90-percent duration.

\section{Safety information}

- Site Hazard Analysis (SHA) that has been approved for this site.

- Emergency contact information - study chief, supervisor, and nearest emergency facilities.

- Traffic-control safety plan showing where to park, placement of flags and cones.

- Specific hazards for this location.

- Location of power lines.

Water-quality-sampling information

- Standard operating procedures (SOPs) and quality-assurance plan (QAP) for the project.

- Sample logs with schedules to collect environmental and quality-control samples.

- Laboratory analysis schedules and associated coding information.

- Bottle types needed for each analytical schedule.

- Analytical services request (ASR) forms and example of a completed form or PCFF.

- Field forms with sections to cover each type of planned sample collection.

- Copies of past field forms, ASRs, and so forth.

- Sampling cross section guidance for equal-discharge increment (EDI) and equal-width increment (EWI) sample collection. Cumulative-discharge curves at approximately 10-, 50-, and 90-percent duration.

- Equipment to use for sampling at all flow regimes.

- Instructions for sampling.

- Equipment logs.

- Mailing labels to and from laboratory.

- Location of nearest Post Office and other shipping agents.

- Historical water-quality information, including typical values for field parameters.

- Instructions for collecting and resetting an autosampler (if applicable). 
Table 1-7. Information to be included in a station folder or well file for groundwater-quality monitoring stations

[Modified from U.S. Geological Survey, 2006b; SIMS, Site Information Management System; GWSI, Groundwater Site Inventory subsystem software within the USGS National Water Information system (NWIS)]

\section{Site information}

- Station description from SIMS.

- Copy of GWSI form 9-1904-A (appendix A) for each station.

- Location information with maps, directions to site, and site sketch map with reference marks and sampling points (see figure 1-2 for examples).

- Datum corrections with record of correction and supporting data.

- Landowner and site-access instructions (for example, "call owner or site operator before arrival, obtain key to unlock security gate"). Copies of agreements for permission to access property and collect samples.

- Photographs of well and vicinity, with reference marks identified.

- Equipment installed at site.

- Well drilling and development information, including construction logs, lithologic and borehole geophysical logs, and well-leveling and surveying record.

- Well dimensions, including casing elevation and screened intervals.

- Location of measuring point in well and other reference marks.

- Aquifer-test results.

\section{Safety information}

- Site Hazard Analysis (SHA) that has been approved for this site.

- Emergency contact information - study chief, supervisor, and nearest emergency facilities.

- Traffic plan showing where to park and placement of flags and cones.

- Specific hazards for this location.

- Location of power lines.

\section{Water-quality-sampling information}

- Standard operating procedures (SOP) and quality-assurance plan (QAP) for the project.

- Sample logs with schedules to collect environmental and quality-control samples.

- Laboratory analysis schedules and associated coding information.

- Bottle types needed for each analytical schedule.

- Analytical services request (ASR) forms and example of a completed form or PCFF.

- Field forms with sections to cover each type of planned sample collection.

- Equipment and instructions for sampling.

- Pumping information such as pump type and operation.

- Location of access point for hose bib or intake for wells with existing pumps.

- Notes on holding tanks and treatment systems.

- Purge log with well-volume calculation and typical recovery rate, where to dispose of purge water, and so forth.

- Protocols for documenting stability in field parameters before sampling.

- Sampling history including past data for field measurements and purge volumes.

- Copies of past field forms, ASRs, and so forth.

- Equipment logs.

- Mailing labels to and from laboratory.

- Location of nearest Post Office and shipping agents.

- Historical water-quality information - past measurements of water levels and field parameters. 


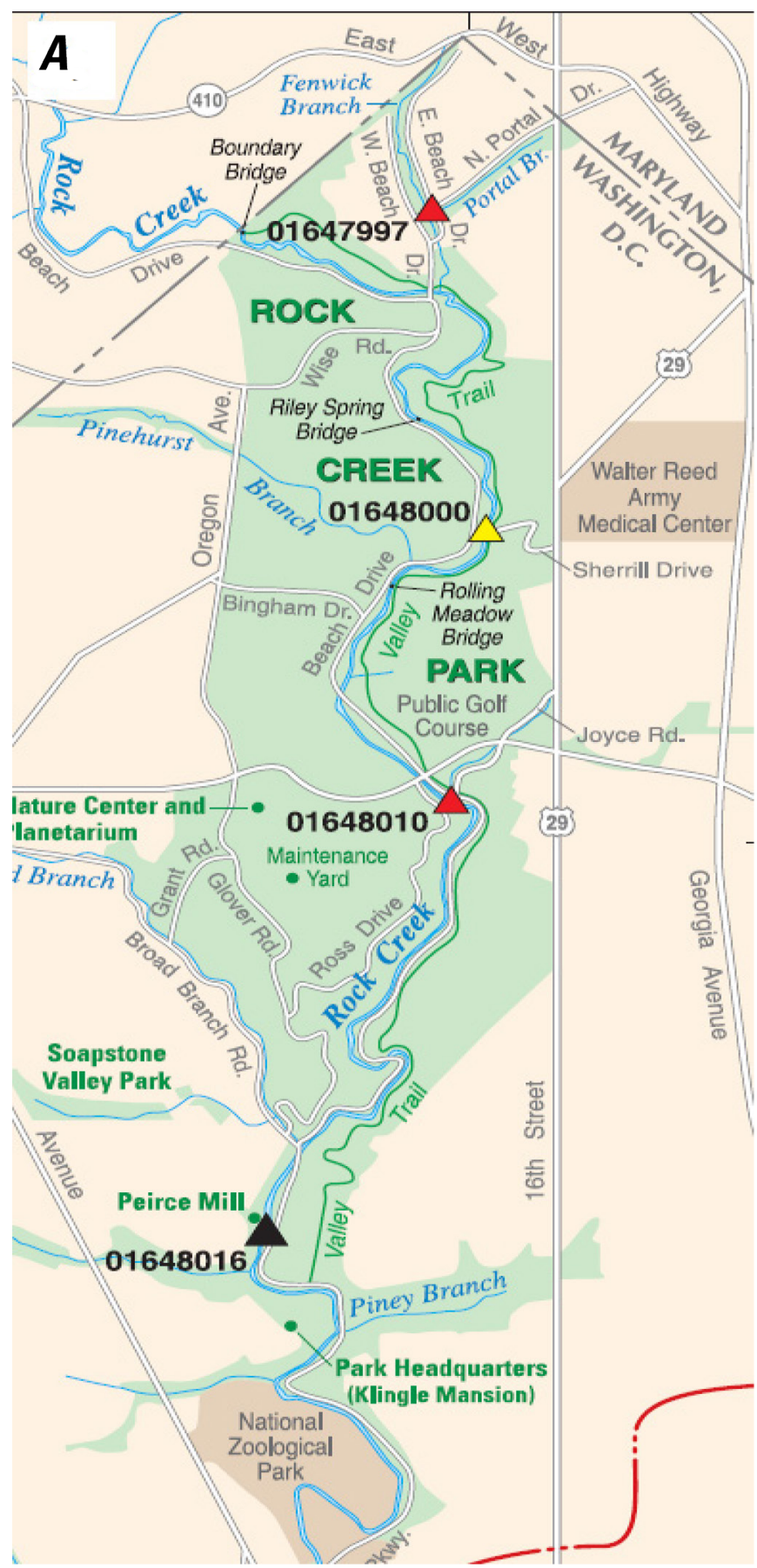

Figure 1-2. Examples of maps to document site locations: $A$, site-location map for Rock Creek Park in Washington, D.C., and $B$, sketch of a well site. 
$\boldsymbol{B}$

Example of well-site sketch (with well-site information).

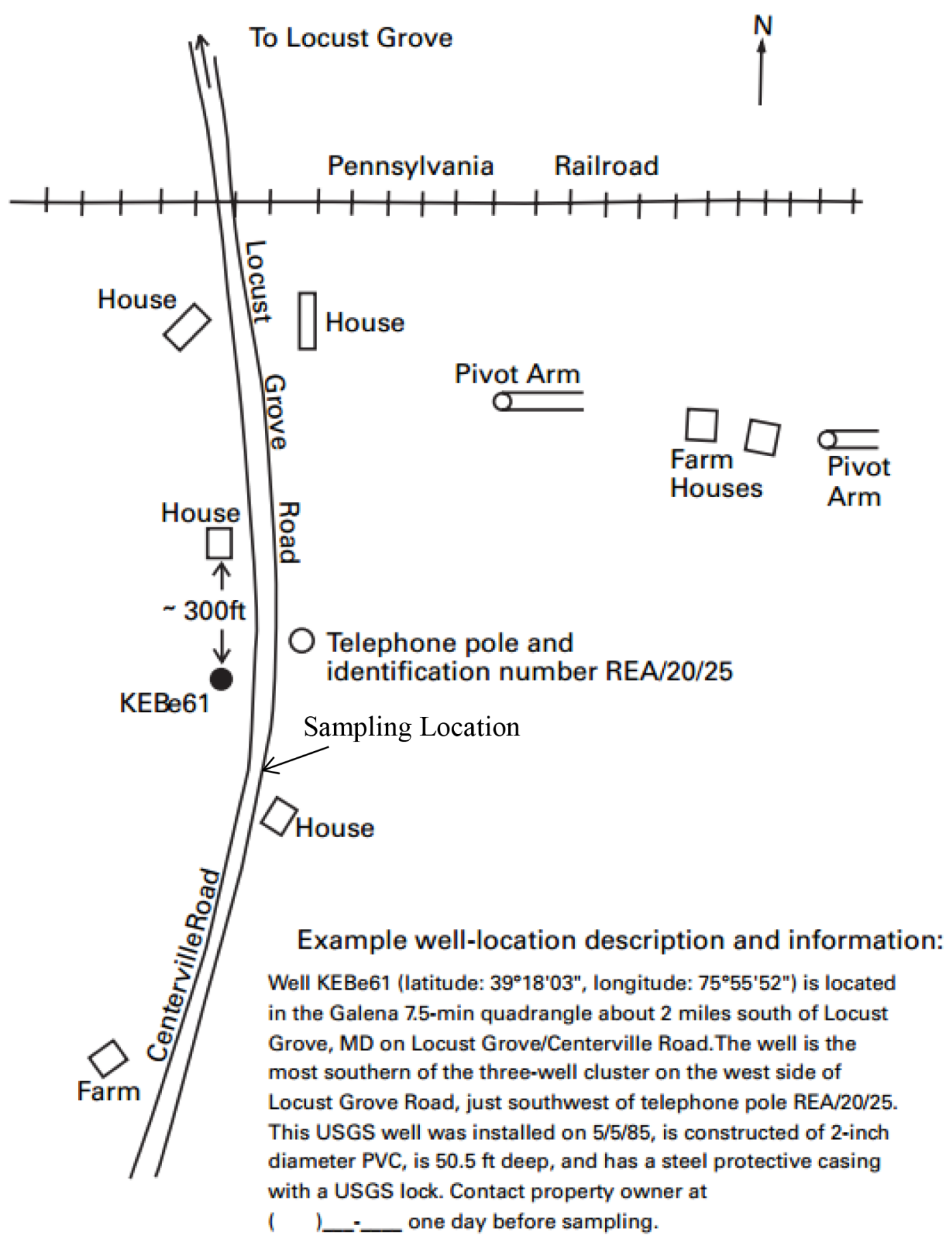

Figure 1-2. Examples of maps to document site locations: $A$, site-location map for Rock Creek Park in Washington, D.C., and $B$, sketch of a well site.-Continued 


\section{References Cited}

Bennett, H., ed., 1986, Concise chemical and technical dictionary (4th ed.): New York, Chemical Publishing Co., $1,271 \mathrm{p}$.

Cunningham, W.L., and Schalk, C.W., 2011, comps., Groundwater technical procedures of the U.S. Geological Survey: U.S. Geological Survey Techniques and Methods, book 1, chap. A1, 151 p., accessed September 11, 2017, at https://pubs.usgs.gov/tm/1a1/.

Hubbard, E.F., 1992, Policy recommendations for management and retention of hydrologic data of the U.S. Geological Survey: U.S. Geological Survey Open-File Report 92-56, 32 p., accessed September 11, 2017, at https://pubs.usgs.gov/of/1992/ofr92-56/.

Lapham, W.W., Wilde, F.D., and Koterba, M.T., 1997, Guidelines and standard procedures for studies of ground-water quality - Selection and installation of wells, and supporting documentation: U.S. Geological Survey Water-Resources Investigations Report 96-4233, 110 p., accessed September 5, 2018, at https://doi.org/10.3133/wri964233.

Mueller, D.K., Schertz, T.L., Martin, J.D., and Sandstrom, M.W., 2015, Design, analysis, and interpretation of field qualitycontrol data for water-sampling projects: U.S. Geological Survey Techniques and Methods, book 4, chap. C4, 54 p., accessed September 11, 2017, at https://dx.doi.org/10.3133/ tm4C4.

U.S. Geological Survey, 1987, Groundwater-Disposition of groundwater observation wells: U.S. Geological Survey Water Resources Division Memorandum 87.17, accessed September 11, 2017, at https://water.usgs.gov/admin/memo/ policy/wrdpolicy87.017.html.

U.S. Geological Survey, 1990, Programs and plans-Policy for permission to sample: U.S. Geological Survey Water Resources Division Memorandum 90.34, accessed September 11, 2017, at https://water.usgs.gov/admin/memo/ policy/wrdpolicy90.034.html.

U.S. Geological Survey, 1992, Policy for management and retention of hydrologic data of the U.S. Geological Survey: U.S. Geological Survey Water Resources Division Memorandum 92.59, accessed September 11, 2017, at https://water.usgs.gov/admin/memo/ policy/wrdpolicy92.059.html.

U.S. Geological Survey, 1994, Legal—Agreement forms 9-1482, 9-1482-A, and 9-1483: U.S. Geological Survey Water Resources Division Memorandum 94.08, accessed September 11, 2017, at https://water.usgs.gov/admin/memo/ policy/wrdpolicy94.008.html.
U.S. Geological Survey, 2002, Water-quality field methods/ National Field Manual for the Collection of Water-Quality Data: U.S. Geological Survey Office of Water Quality Technical Memorandum 2002.13, accessed September 11, 2017, at https://water.usgs.gov/admin/memo/QW/ qw02.13.html.

U.S. Geological Survey, 2003, Agreement forms for gaging station and observation-well installations and transfers: U.S. Geological Survey Office of Ground Water Technical Memorandum 2003.03, accessed September 11, 2017, at https://water.usgs.gov/admin/memo/GW/gw03.03.html. [Also released simultaneously as U.S. Geological Survey Office of Surface Water Technical Memorandum 2003.08.]

U.S. Geological Survey, 2006a, Collection of water samples (ver. 2.0, September 2006): U.S. Geological Survey Techniques of Water-Resources Investigations, book 9, chap. A4, accessed September 11, 2017, at http://pubs.water.usgs.gov/ twri9A4/.

U.S. Geological Survey, 2006b, Storage of water-level data for ground water: U.S. Geological Survey Office of Water Quality Technical Memorandum 2006.01, accessed September 11, 2017, at https://water.usgs.gov/admin/ $\mathrm{memo} / \mathrm{QW} / \mathrm{qw}$ 06.01.html. [Also released simultaneously as U.S. Geological Survey Office of Groundwater Technical Memorandum 2006.01.]

U.S. Geological Survey, 2008a, Appropriate data storage in the National Water Information System (NWIS): U.S. Geological Survey Office of Water Quality Technical Memorandum 2008.05, accessed September 11, 2017, at https://water.usgs.gov/admin/memo/QW/qw08.05.html.

U.S. Geological Survey, 2008b, Obtaining permission for access to private lands: U.S. Geological Survey Manual, chap. 500.11, accessed September 11, 2017, at https://www2.usgs.gov/usgs-manual/500/500-11.html.

U.S. Geological Survey, 2008c, Safety and health training, chap. 14 of Occupational Safety and Health Program requirements handbook: U.S. Geological Survey Manual, handbook 445-2-H, accessed September 11, 2017, at https://www2.usgs.gov/usgs-manual/handbook/hb/445-2-h/ ch14.html.

U.S. Geological Survey, 2010a, Continuous records processing of all water time series data: U.S. Geological Survey Water Resources Division Policy Numbered Memorandum 2010.02, accessed September 11, 2017, at https://water.usgs.gov/ $\mathrm{admin} / \mathrm{memo} /$ policy/wrdpolicy10.02.html. 
U.S. Geological Survey, 2010b, Processing and publication of discharge and stage data collected in tidally influenced areas: U.S. Geological Survey Office of Surface Water Technical Memorandum 2010.08 (revised September 22, 2011), accessed September 11, 2017, at https://water.usgs.gov/ $\mathrm{admin} / \mathrm{memo} / \mathrm{SW} / \mathrm{sw} 10.08$ tidal_policy_memo-9-26-11with_tracked_revisions.pdf.

U.S. Geological Survey, 2011, Fundamental Science Practices-Planning and conducting data collection and research: U.S. Geological Survey Manual, chap. 502.2, accessed September 11, 2017, at https://www2.usgs.gov/ usgs-manual/500/502-2.html.

U.S. Geological Survey, 2012, Update of policy on review and publication of discrete water data: U.S. Geological Survey Office of Water Quality Technical Memorandum 2012.03, accessed September 11, 2017, at https://water.usgs.gov/ $\mathrm{admin} / \mathrm{memo} / \mathrm{QW} / \mathrm{qw} 12.03$.pdf. [Also released simultaneously as U.S. Geological Survey Office of Groundwater Technical Memorandum 2012.03 and U.S. Geological Survey Office of Surface Water Technical Memorandum 2012.03.]

U.S. Geological Survey, 2014a, Revised template for preparing a quality-assurance plan for water-quality activities: U.S. Geological Survey Office of Water Quality Technical Memorandum 2014.02, accessed September 11, 2017, at https://water.usgs.gov/admin/memo/QW/qw2014.02.pdf.

U.S. Geological Survey, 2014b, Safety and health for field operations: U.S. Geological Survey Manual, handbook 445-3-H, 336 p., accessed September 11, 2017, at https://www2.usgs.gov/usgs-manual/handbook/ hb/445-3-h.pdf.

U.S. Geological Survey, 2014c, Updated policy for the evaluation and approval of analytical laboratory performance for Water Mission Area projects and programs: U.S. Geological Survey Office of Water Quality Technical Memorandum 2014.01, accessed September 11, 2017, at https://water.usgs.gov/admin/memo/QW/qw2014.01.pdf.

U.S. Geological Survey, 2015, Effective immediatelyRequired use of the revised analytical services request (ASR) form for samples received at the National WaterQuality Laboratory (NWQL): U.S. Geological Survey Office of Water Quality Technical Memorandum 2015.02, accessed September 11, 2017, at https://water.usgs.gov/ admin/memo/QW/qw2015.02.pdf.

U.S. Geological Survey, 2016a, Fundamental Science Practices-Review, approval, and release of information products: U.S. Geological Survey Manual, chap. 502.4, accessed September 25, 2017, at https://www2.usgs.gov/ usgs-manual/500/502-4.html.
U.S. Geological Survey, 2016b, Guidance for the collection and disposition of USGS water-quality data recordsSpecifically addressing electronic records for field notebooks and calibration notebooks: U.S. Geological Survey Office of Water Quality Technical Memorandum 2016.09, accessed September 11, 2017, at https://water.usgs.gov/ $\mathrm{admin} / \mathrm{memo} / \mathrm{QW} / \mathrm{qw} 2016.09 . \mathrm{pdf}$.

U.S. Geological Survey, 2016c, Water Mission Area policy on accepting furnished records: U.S. Geological Survey Office of Water Quality Technical Memorandum 2016.08, accessed September 11, 2017, at https://water.usgs.gov/admin/memo/ QW/qw2016.08.pdf. [Also released simultaneously as U.S. Geological Survey Office of Groundwater Technical Memorandum 2016.01 and U.S. Geological Survey Office of Surface Water Technical Memorandum 2016.04.]

U.S. Geological Survey, 2017a, Clarification of Water Mission Area policy on continuous records processing of time-series data-Categorization of groundwater, surface-water, and water-quality sites/records: U.S. Geological Survey Office of Water Quality Technical Memorandum 2017.02, accessed September 11, 2017, at https://water.usgs.gov/admin/memo/ QW/qw2017.02.pdf. [Also released simultaneously as U.S. Geological Survey Office of Groundwater Technical Memorandum 2017.01 and U.S. Geological Survey Office of Surface Water Technical Memorandum 2017.05.]

U.S. Geological Survey, 2017b, Fundamental Science Practices-Review and approval of scientific data for release: U.S. Geological Survey Manual, chap. 502.8, accessed September 11, 2017, at https://www2.usgs.gov/ usgs-manual/500/502-8.html.

U.S. Geological Survey, 2017c, Fundamental Science Practices-Scientific data management: U.S. Geological Survey Manual, chap. 502.6, accessed September 11, 2017, at https://www2.usgs.gov/usgs-manual/500/502-6.html.

U.S. Geological Survey, 2017d, Procedures for processing, approving, publishing, and auditing time-series records for water data: U.S. Geological Survey Office of Water Quality Technical Memorandum 2017.07, accessed August 10, 2018, at https://water.usgs.gov/osw/time-seriesguidance/SW_2017.10+GW_2017.03+WQ_2017.07.pdf. [Also released simultaneously as U.S. Geological Survey Office of Groundwater Technical Memorandum 2017.03 and U.S. Geological Survey Office of Surface Water Technical Memorandum 2017.10.]

U.S. Geological Survey, 2018a, General introduction for the "National Field Manual for the Collection of WaterQuality Data" (ver. 1.1, June 2018): U.S. Geological Survey Techniques and Methods, book 9, chap. A0, 4 p., accessed June 22, 2018, at https://doi.org/10.3133/tm9A0. 
U.S. Geological Survey, 2018b, U.S. Geological Survey records disposition schedules: U.S. Geological

Survey Manual web page, accessed June 13, 2018, at https://www2.usgs.gov/usgs-manual/schedule/index.html.

U.S. Geological Survey [variously dated], Occupational Safety and Health Program requirements handbook: U.S. Geological Survey Manual, handbook SM 445-2-H, accessed September 11, 2017, at https://www2.usgs.gov/ usgs-manual/handbook/hb/445-2-h.html.
Wilde, F.D., 2005, Preparations for water sampling (ver. 2.0): U.S. Geological Survey Techniques of WaterResources Investigations, book 9, chap. A1, accessed September 11, 2017, at https://pubs.water.usgs.gov/ twri9A1/. 



\section{Appendix A. Forms to Establish a New Site in the Groundwater Site Inventory (GWSI)}

Figure 1-A.1. Form 9-1904-A-U.S. Geological Survey schedule for establishing a new surfacewater site in the Groundwater Site Inventory (GWSI)

Figure 1-A.2. Form 9-1904-A-U.S. Geological Survey schedule for establishing a new groundwater site in the Groundwater Site Inventory (GWSI) 
FORM NO. 9-1904-A

Revised March 2015, NWIS 5.2

Coded by

Checked by

Entered by

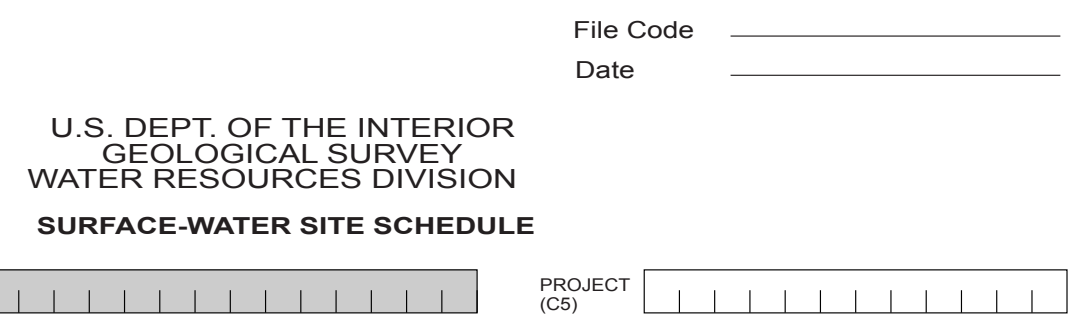

AGENCY
CODE (C4)
STATION NAME (C12/900)

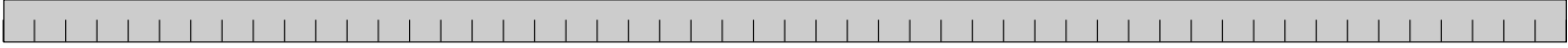

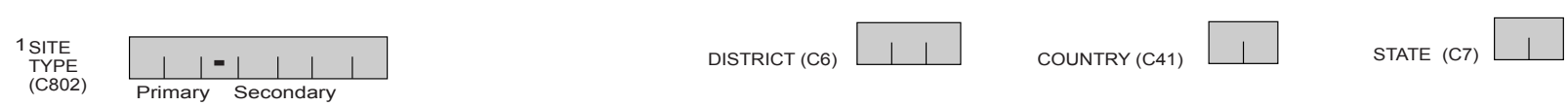

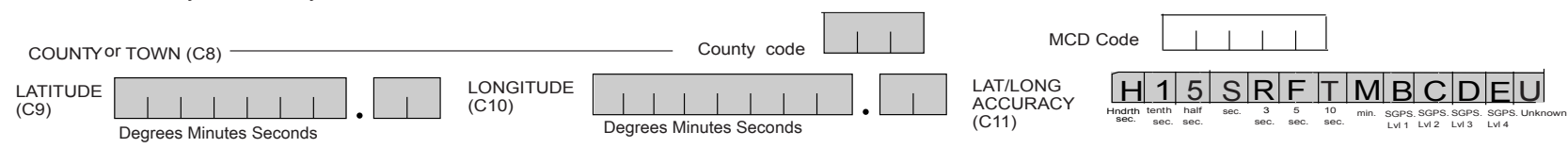

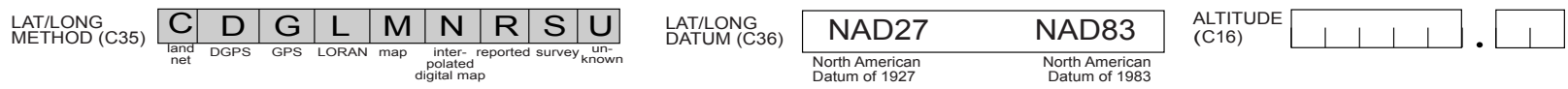

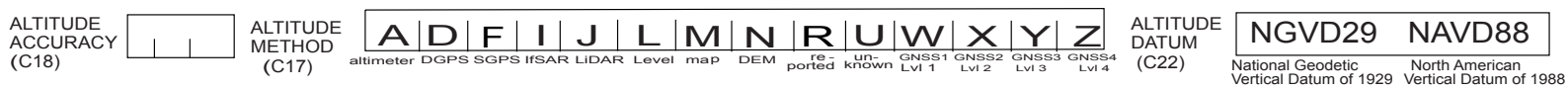

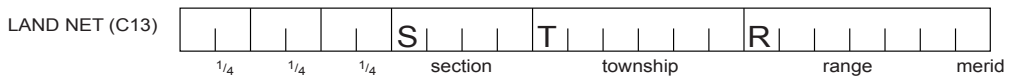

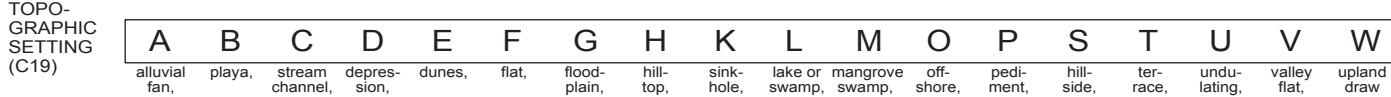

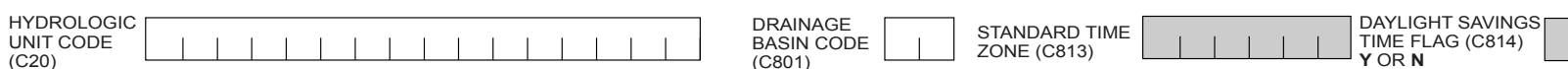

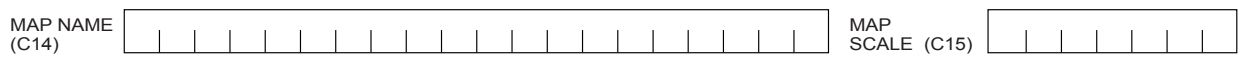

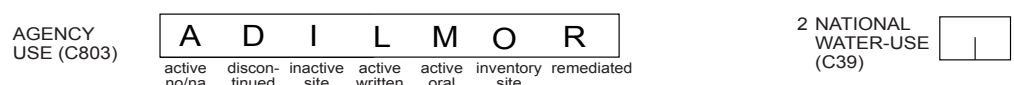

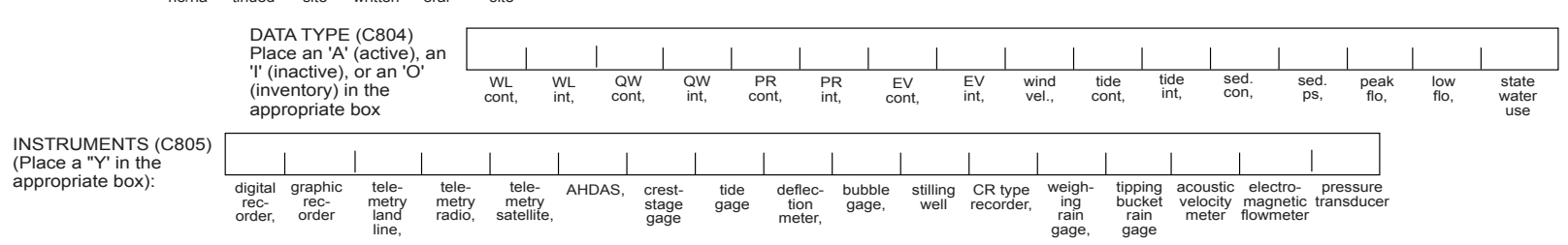

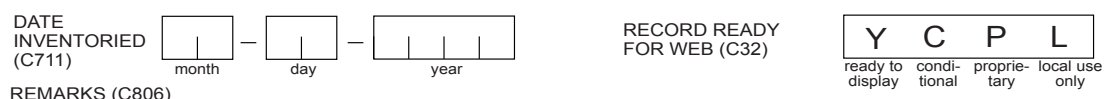

REMARKS (C806)

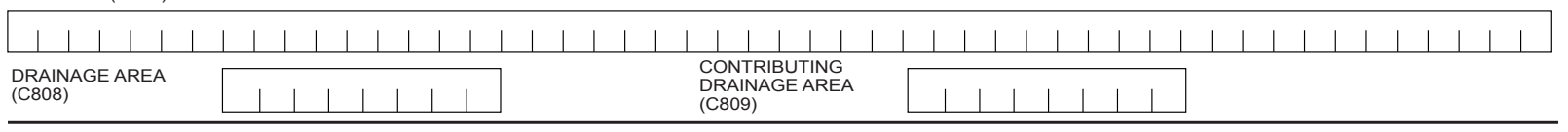

\section{FOOTNOTES}

1SITE TYPE (partial list) --see GWSI User's Manual (http://wwwnwis.er.usgs.gov/currentdocs/gw/GW.user.book.htm/) for complete list
(C802)

GL ${ }^{(\mathrm{C} 802)}$ Glacier LA-SR Shore $\quad$ FA-LF Landfill

WE Wetland $\quad$ OC Ocean $\quad$ SPS Septic Syste

$\begin{array}{llll}\text { AT } & \text { Atmosphere } & \text { OC-CO } & \text { Coastal } \\ \text { ES } & \text { Estuary } & \text { LK } & \text { Lake, Reser }\end{array}$

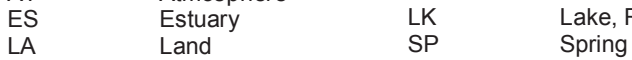

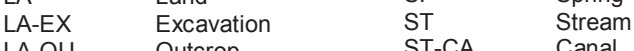

$\begin{array}{llll}\text { LA-OU } & \text { Outcrop } & \text { ST-CA } & \text { Canal } \\ \text { LA-SNK } & \text { Sinkhole } & \text { ST-DCH } & \text { Ditch }\end{array}$

$\begin{array}{llll}\text { LA-SNK } & \text { Sinkhole } & \text { ST-DCH } & \text { Ditch } \\ \text { LA-SH } & \text { Soil hole } & \text { ST-TS } & \text { Tidal stream }\end{array}$

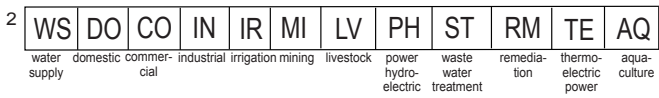

C22 Other (see manual for codes)

C36 Other (see manual for codes)

C39 is mandatory for all sites having data in SWUDS.

Figure 1-A.1. Form 9-1904-A-U.S. Geological Survey schedule for establishing a new surface-water site in the Groundwater Site Inventory (GWSI). 


\section{SURFACE-WATER SITE DATA

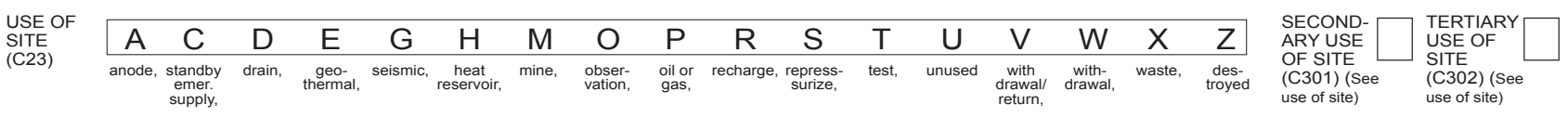

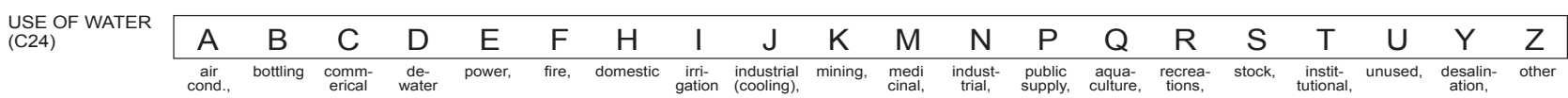

Beginning with NWIS 4.2, several tables were made accessible to surface-water sites. Most of these tables relate to ground-water elements and will have limited applicability to surface-water sites. The tables of most common use for surface-water sites are listed below. Others that are available but will be used rarely include CONS, LIFT, REPR, NETW, REMARKS, VISIT, GEOH, AQFR, HYDR, OBS, DISC, and COEFF. See the Ground-Water User's Manual for more information on these tables.

\section{MISCELLANEOUS OWNER DATA}

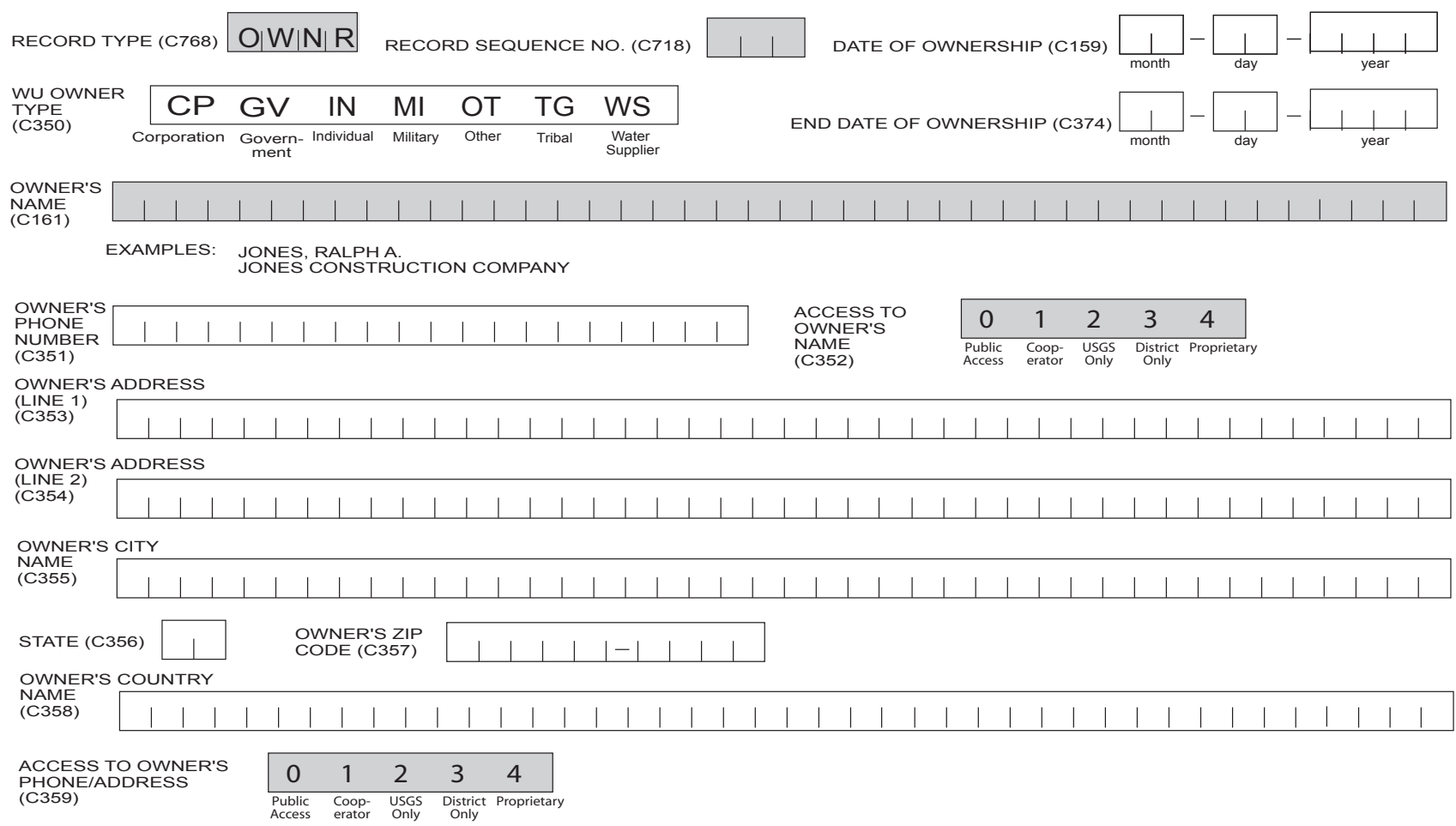

MISCELLANEOUS OTHER ID DATA (2 sets shown)

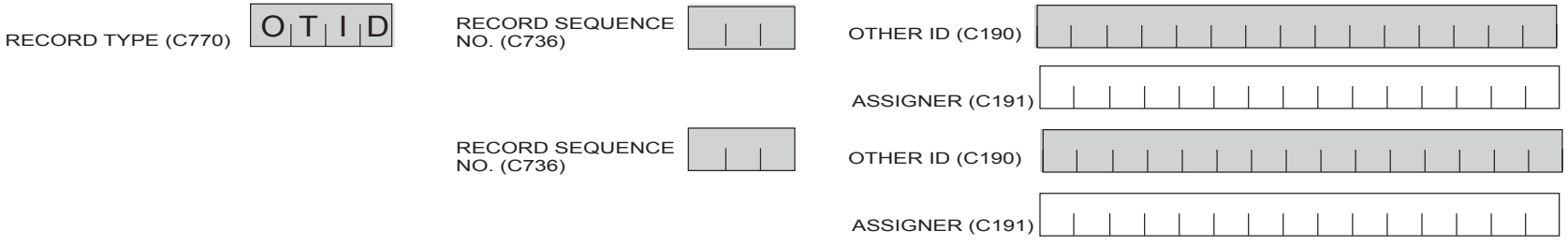

Figure 1-A.1. Form 9-1904-A-U.S. Geological Survey schedule for establishing a new surface-water site in the Groundwater Site Inventory (GWSI).-Continued 


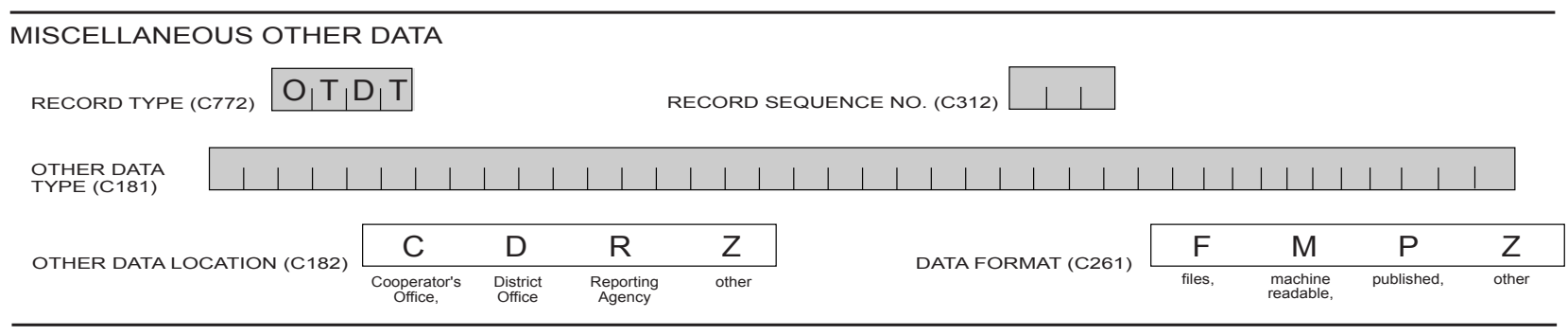




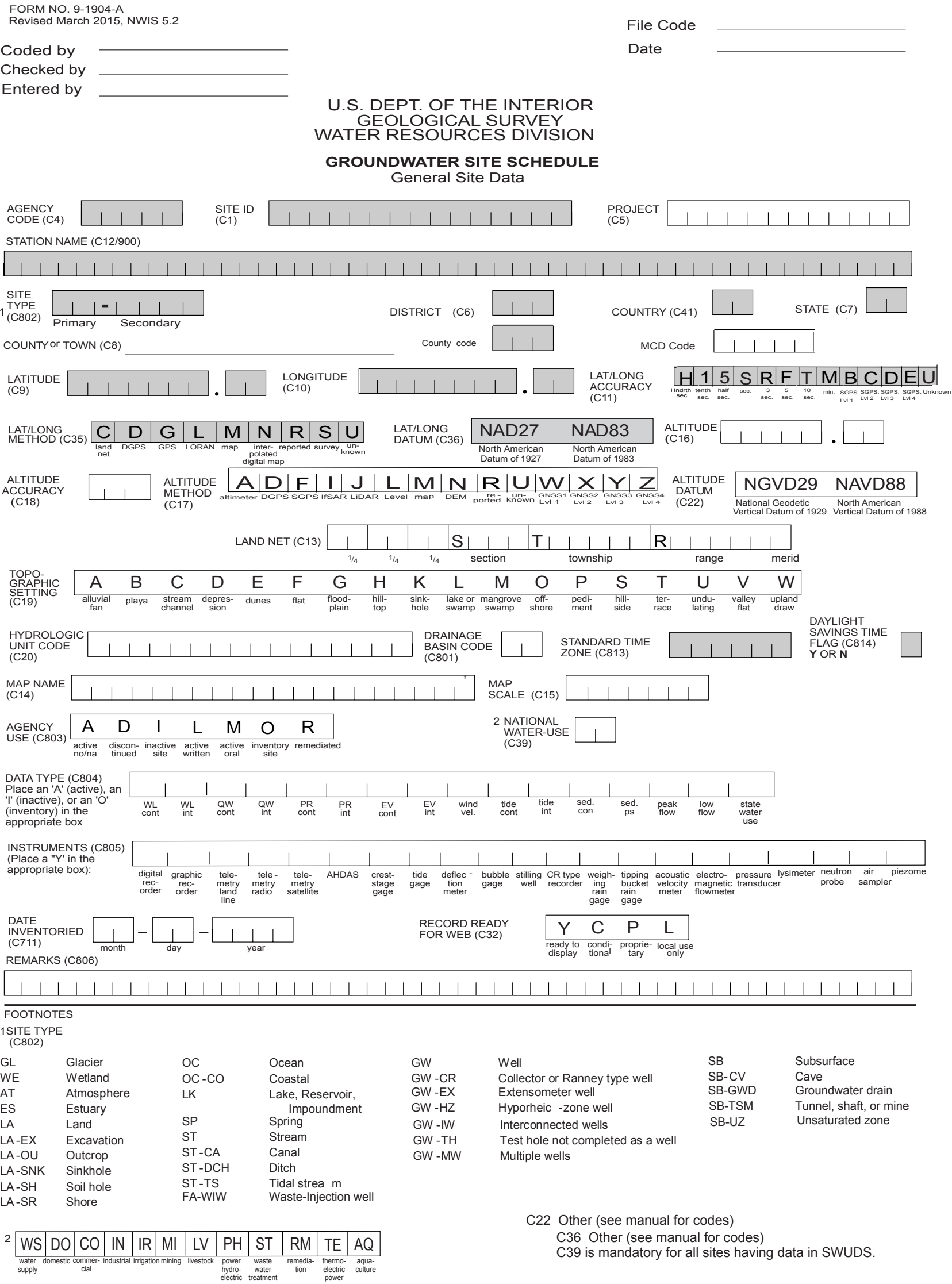

Figure 1-A.2. Form 9-1904-A-U.S. Geological Survey schedule for establishing a new groundwater site in the Groundwater Site Inventory (GWSI). 

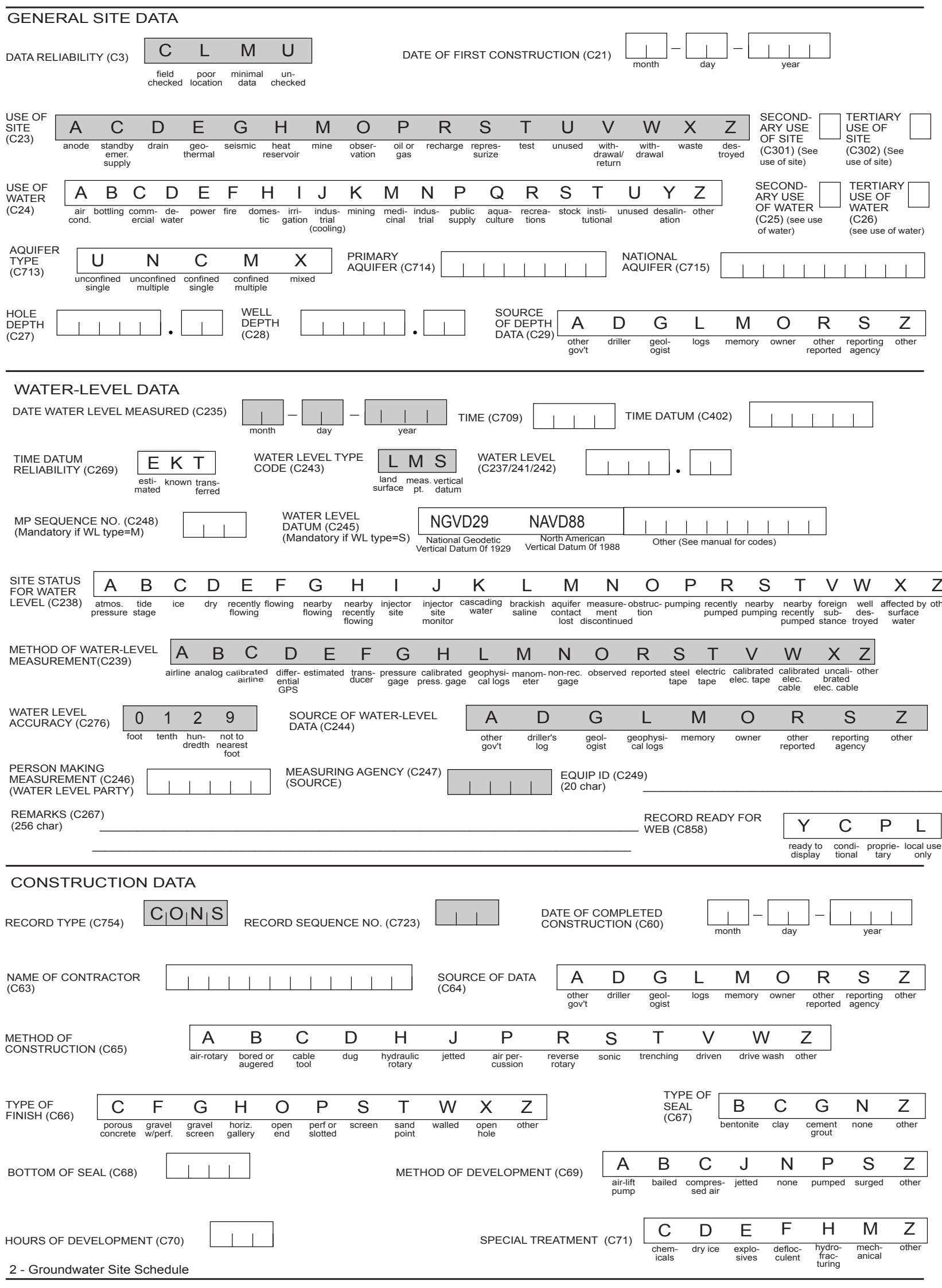

Figure 1-A.2. Form 9-1904-A-U.S. Geological Survey schedule for establishing a new groundwater site in the Groundwater Site Inventory (GWSI).-Continued 


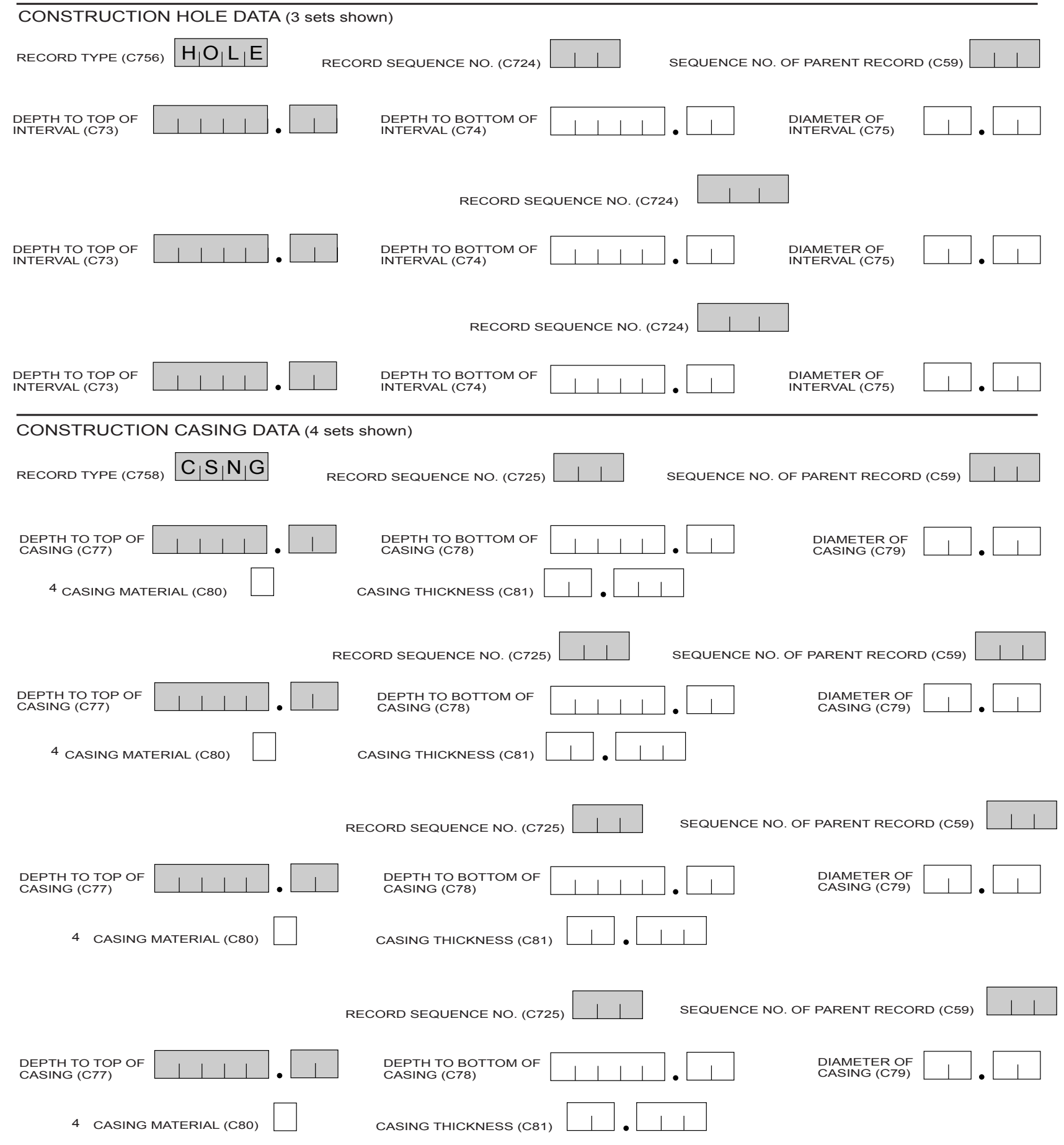

FOOTNOTE:

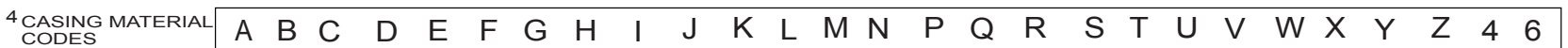

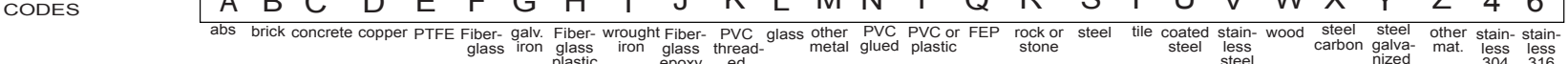

Figure 1-A.2. Form 9-1904-A-U.S. Geological Survey schedule for establishing a new groundwater site in the Groundwater Site Inventory (GWSI).-Continued 


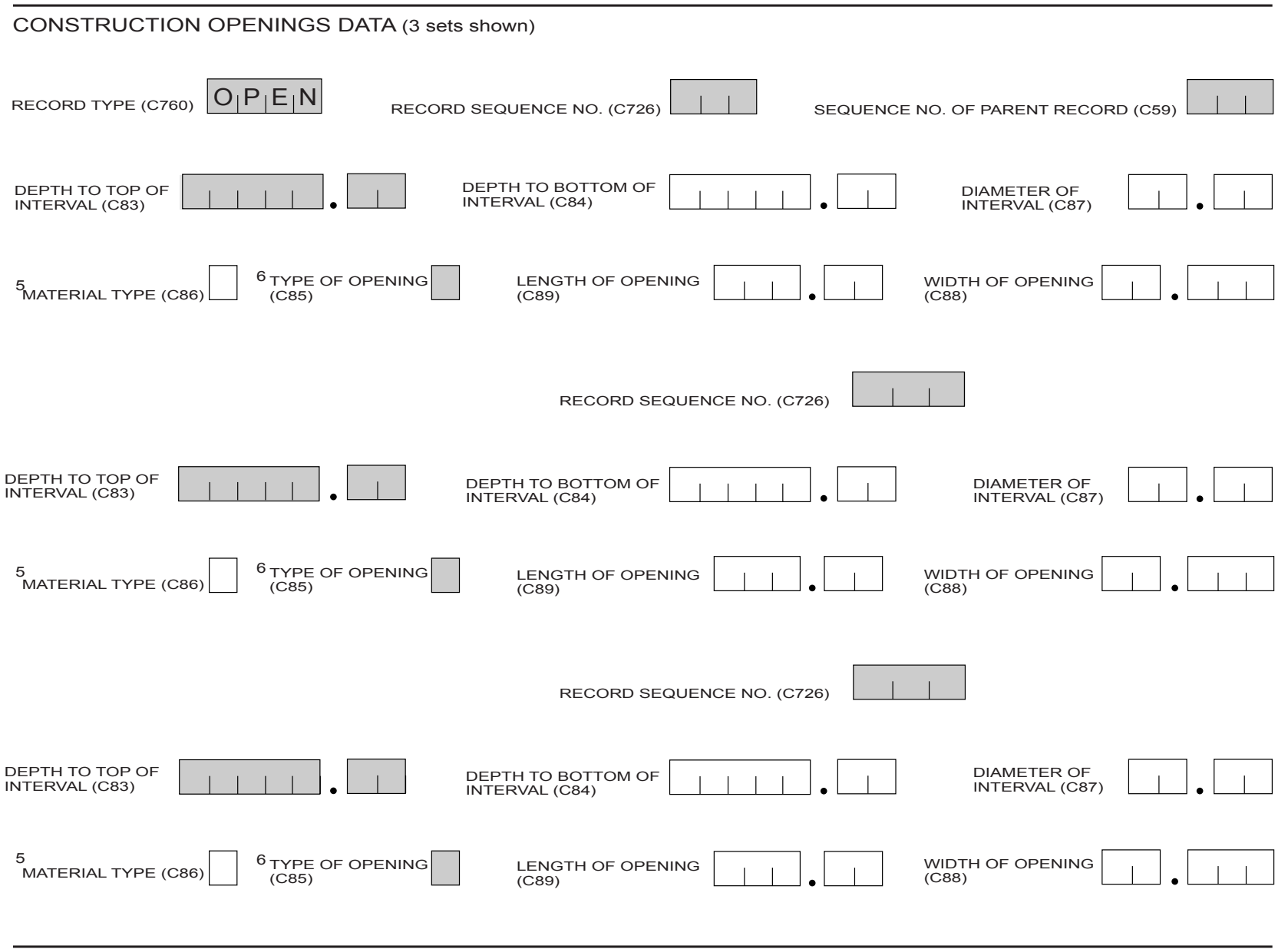

FOOTNOTES:

5 TYPE OF MATERIAL CODES FOR

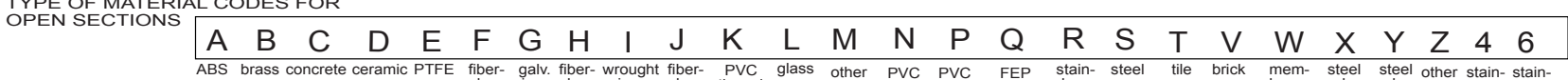

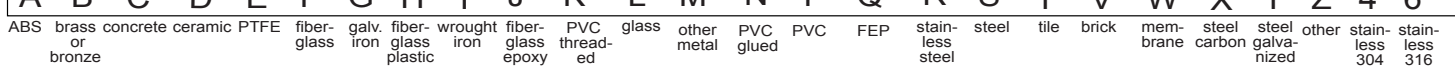

6 TYPE OF OPENINGS CODES

\begin{tabular}{|cccccccccc|}
\hline $\mathrm{F}$ & $\mathrm{L}$ & $\mathrm{M}$ & $\mathrm{P}$ & $\mathrm{R}$ & $\mathrm{S}$ & $\mathrm{T}$ & $\mathrm{W}$ & $\mathrm{X}$ & $\mathrm{Z}$ \\
\hline $\begin{array}{c}\text { fractured } \\
\text { rock }\end{array}$ & $\begin{array}{l}\text { louvered or } \\
\text { shutter-type }\end{array}$ & $\begin{array}{c}\text { mesh } \\
\text { screen }\end{array}$ & $\begin{array}{c}\text { perforated, } \\
\text { porous or } \\
\text { slotted }\end{array}$ & $\begin{array}{c}\text { wire- } \\
\text { wound } \\
\text { screen }\end{array}$ & $\begin{array}{c}\text { screen } \\
\text { (unk.) }\end{array}$ & $\begin{array}{c}\text { sand } \\
\text { point } \\
\text { screen }\end{array}$ & $\begin{array}{c}\text { walled or } \\
\text { shored }\end{array}$ & $\begin{array}{c}\text { open } \\
\text { hole }\end{array}$ & other \\
\hline
\end{tabular}

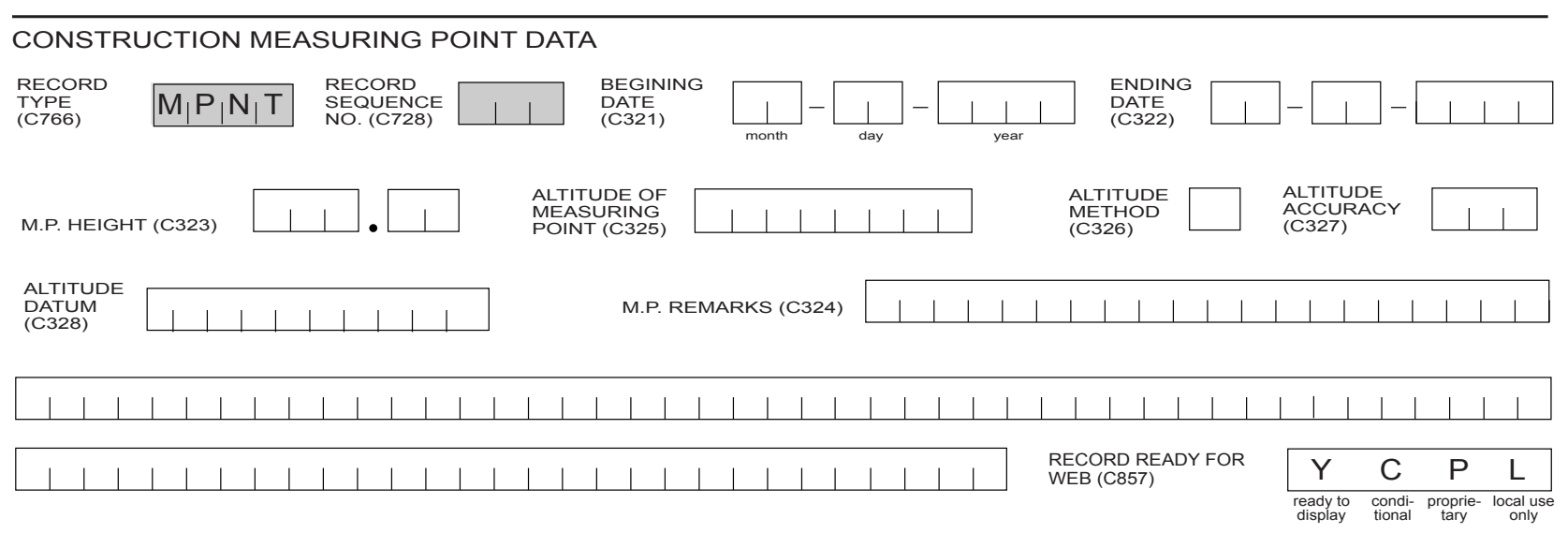

4 - Groundwater Site Schedule

Figure 1-A.2. Form 9-1904-A-U.S. Geological Survey schedule for establishing a new groundwater site in the Groundwater Site Inventory (GWSI).-Continued 


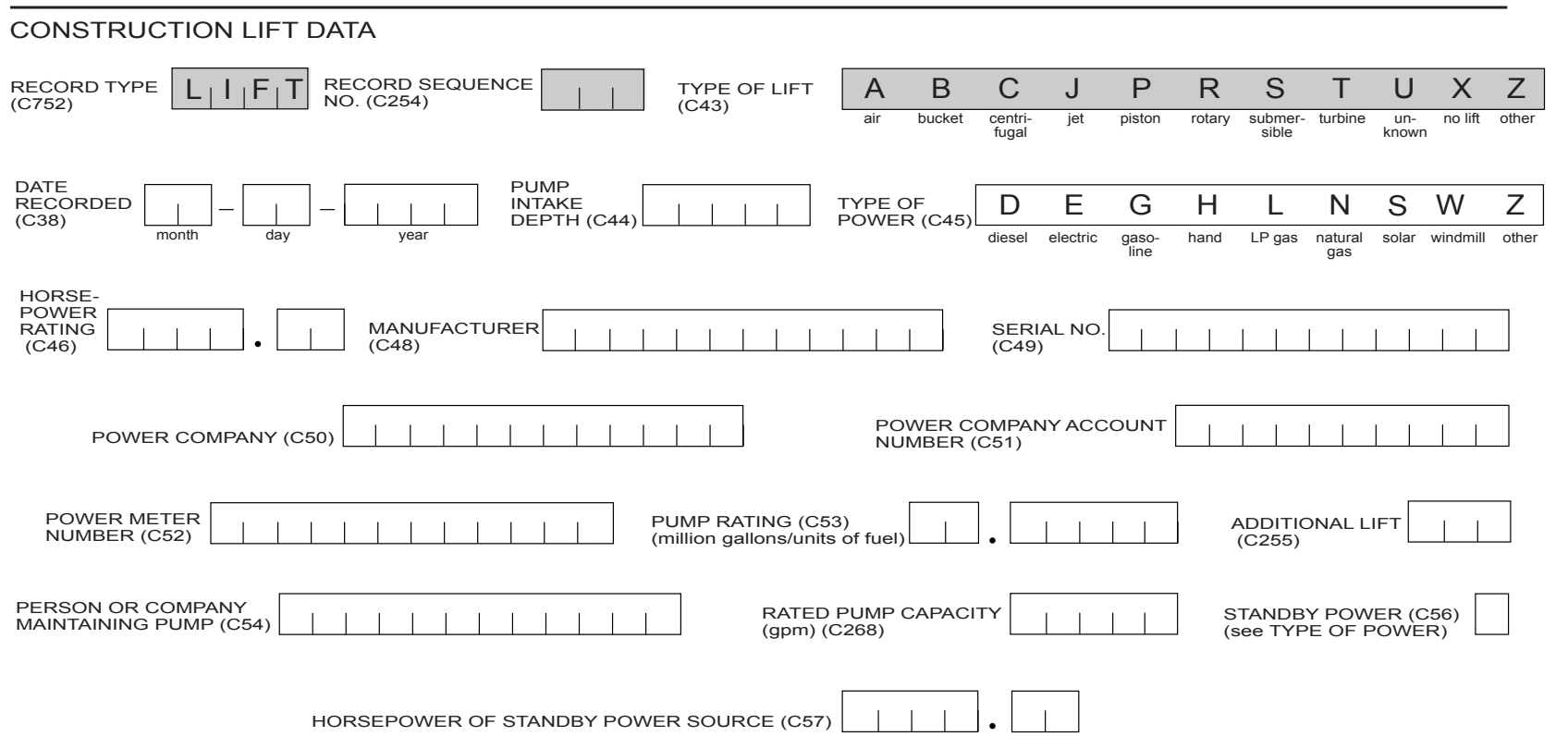

MISCELLANEOUS OWNER DATA

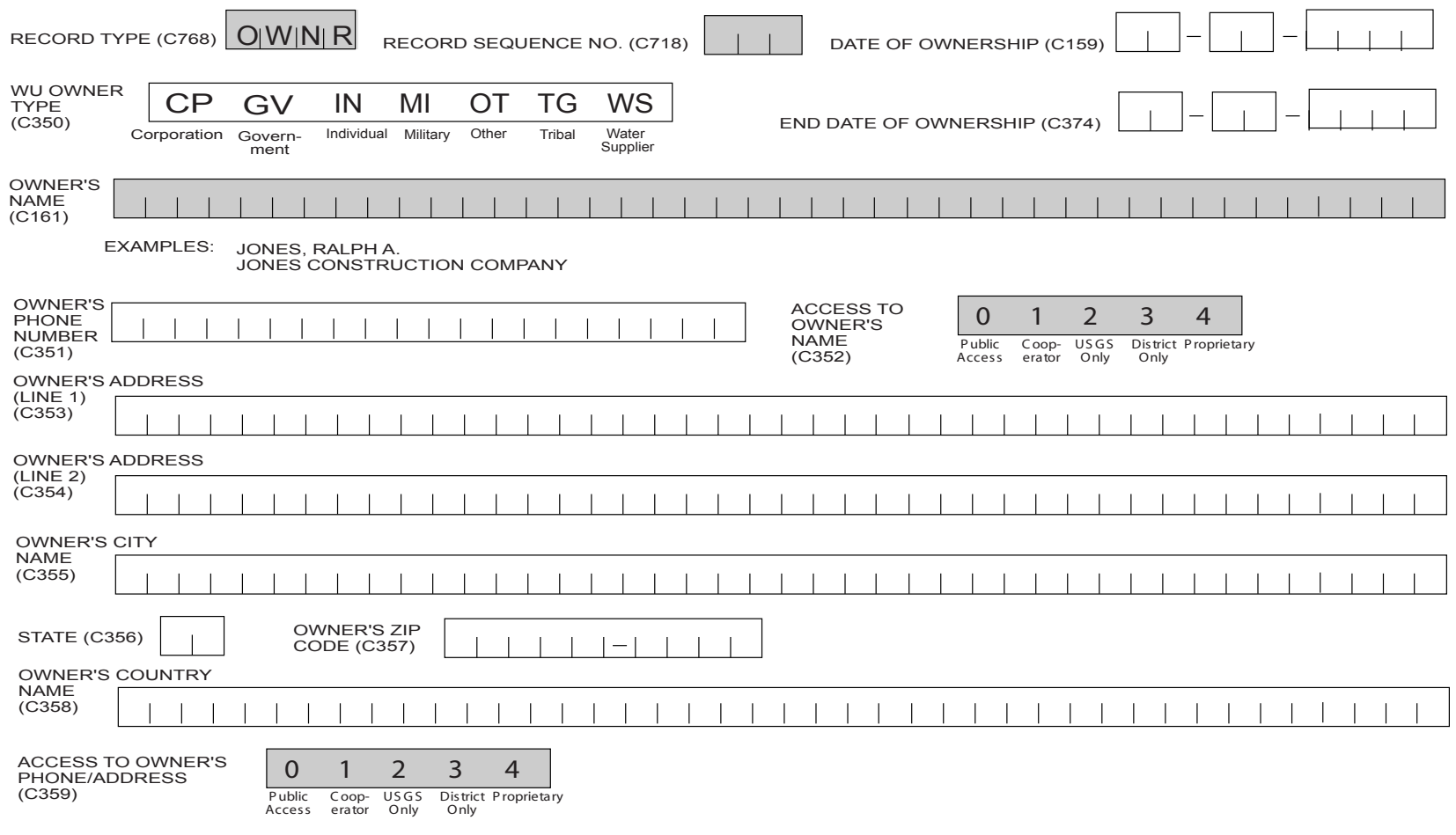

MISCELLANEOUS VISIT DATA

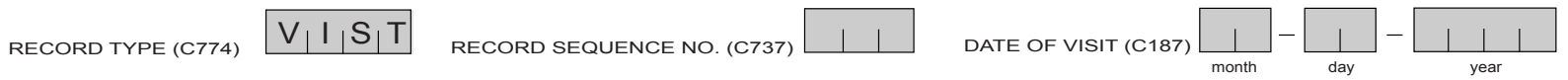

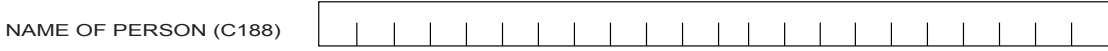

Figure 1-A.2. Form 9-1904-A-U.S. Geological Survey schedule for establishing a new groundwater site in the Groundwater Site Inventory (GWSI).-Continued 
MISCELLANEOUS OTHER ID DATA (2 sets shown)

O T,I D RECORD SEQUENCE NO. (C736)

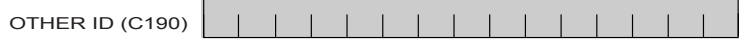

ReORD TYPE (C770)
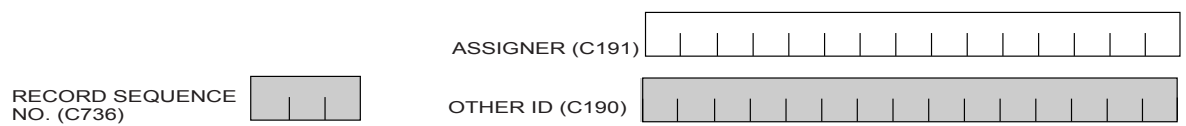
RECORD SEQUENCE $1 \mid 1$
NO. (C736) OTHER ID (C190)

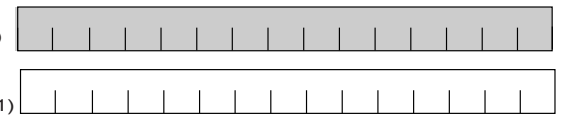

MISCELLANEOUS OTHER DATA

\begin{tabular}{|c|c|}
\hline & \\
\hline RECORD TYPE (C772) & $\mathrm{O}_{\mid} \mathrm{T}, \mathrm{D} \mid \mathrm{T}$ \\
\hline
\end{tabular}

\begin{tabular}{|c|c|c|c|c|c|c|c|c|c|}
\hline $\begin{array}{l}\text { OTHER DATA } \\
\text { TYPE (C181) }\end{array}$ & $\perp$ & 1 & 1 & $\perp$ & $1|1|+|1|$ & & 11 & 11 & \\
\hline \multirow{2}{*}{ OTHER DATA LOCATION (C182) } & $\mathrm{C}$ & $\mathrm{D}$ & $\mathrm{R}$ & Z & \multirow{2}{*}{ DATA FORMAT (C261) } & $\mathrm{F}$ & $\mathrm{M}$ & $P$ & Z \\
\hline & $\begin{array}{l}\text { Cooperator's } \\
\text { Office, }\end{array}$ & $\begin{array}{l}\text { District } \\
\text { Office }\end{array}$ & $\begin{array}{l}\text { Reporting } \\
\text { Agency }\end{array}$ & other & & files, & $\begin{array}{l}\text { machine } \\
\text { readable, }\end{array}$ & published, & other \\
\hline
\end{tabular}
MISCELLANEOUS LOGS DATA ( 3 sets shown)

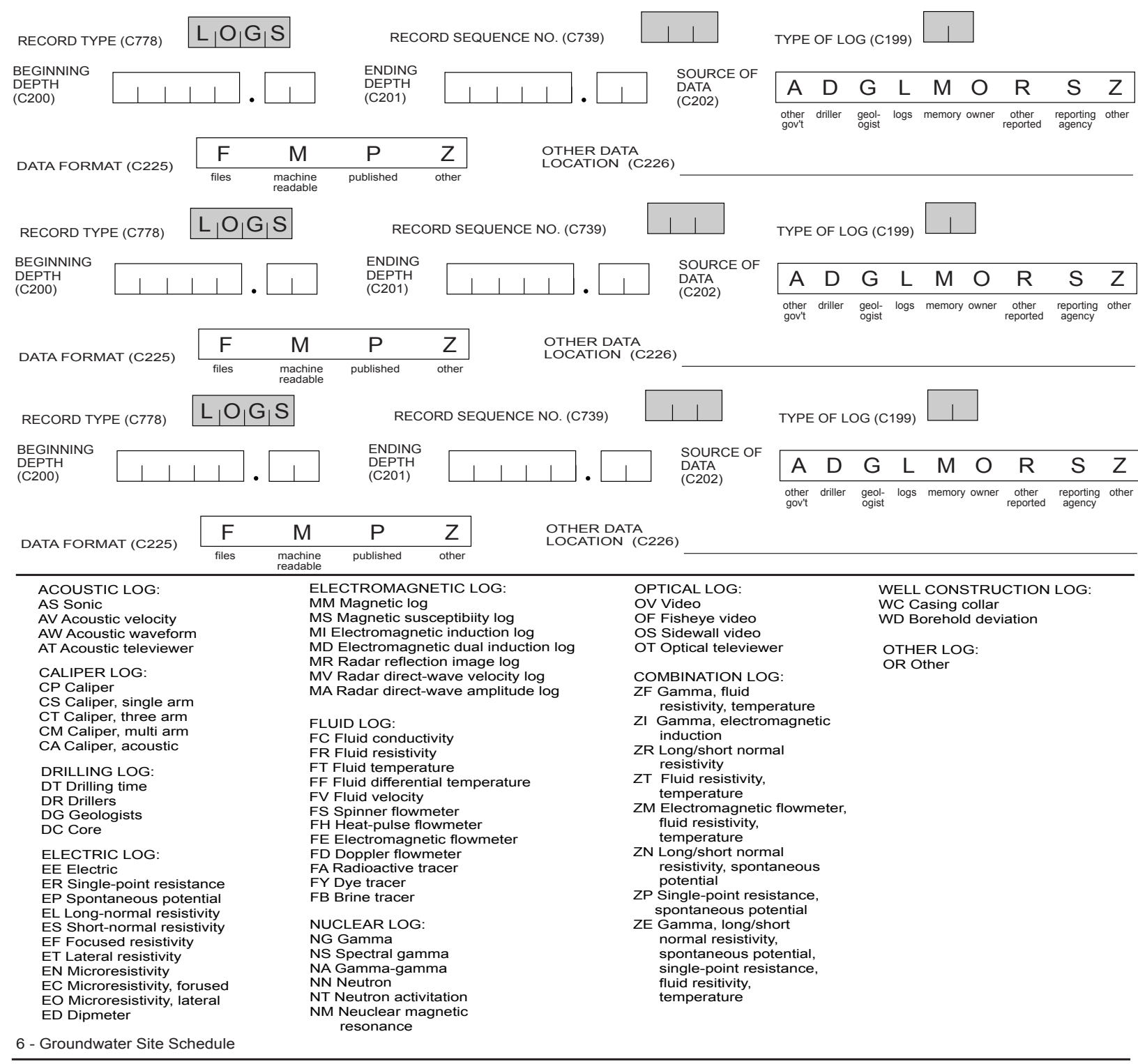

Figure 1-A.2. Form 9-1904-A-U.S. Geological Survey schedule for establishing a new groundwater site in the Groundwater Site Inventory (GWSI).-Continued 


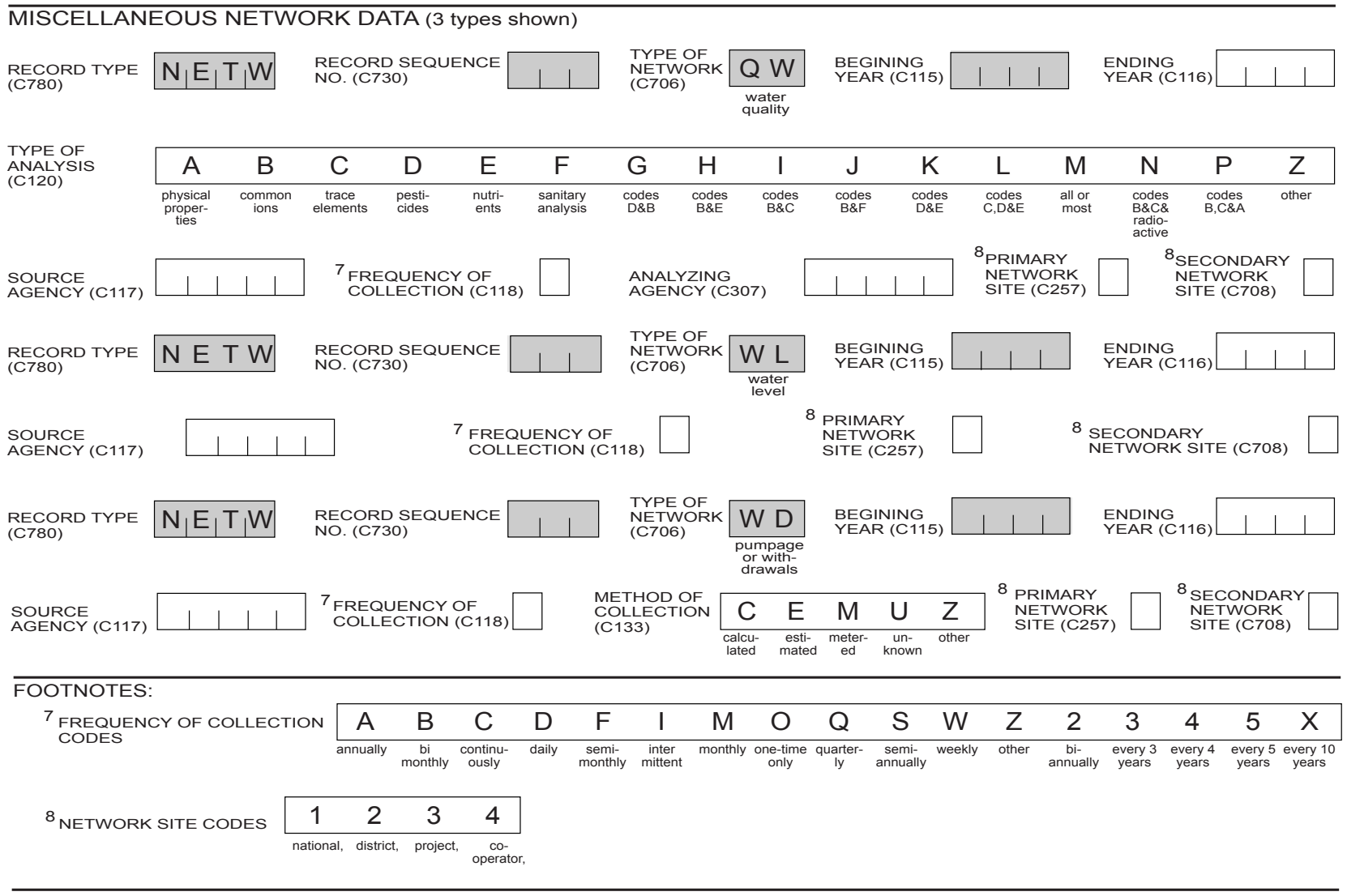

MISCELLANEOUS REMARKS DATA (4 types shown)

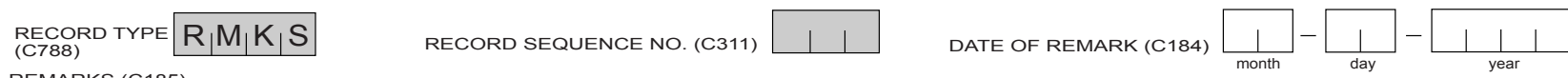
REMARKS (C185)

Subsequent entries may be used to continue the remark. Miscellaneous remarks field is limited to 256 characters.

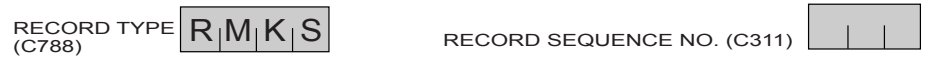

REMARKS (C185)

DATE OF REMARK (C184)

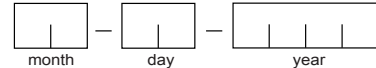

Subsequent entries may be used to continue the remark. Miscellaneous remarks field is limited to 256 characters.

Figure 1-A.2. Form 9-1904-A-U.S. Geological Survey schedule for establishing a new groundwater site in the Groundwater Site Inventory (GWSI).-Continued 


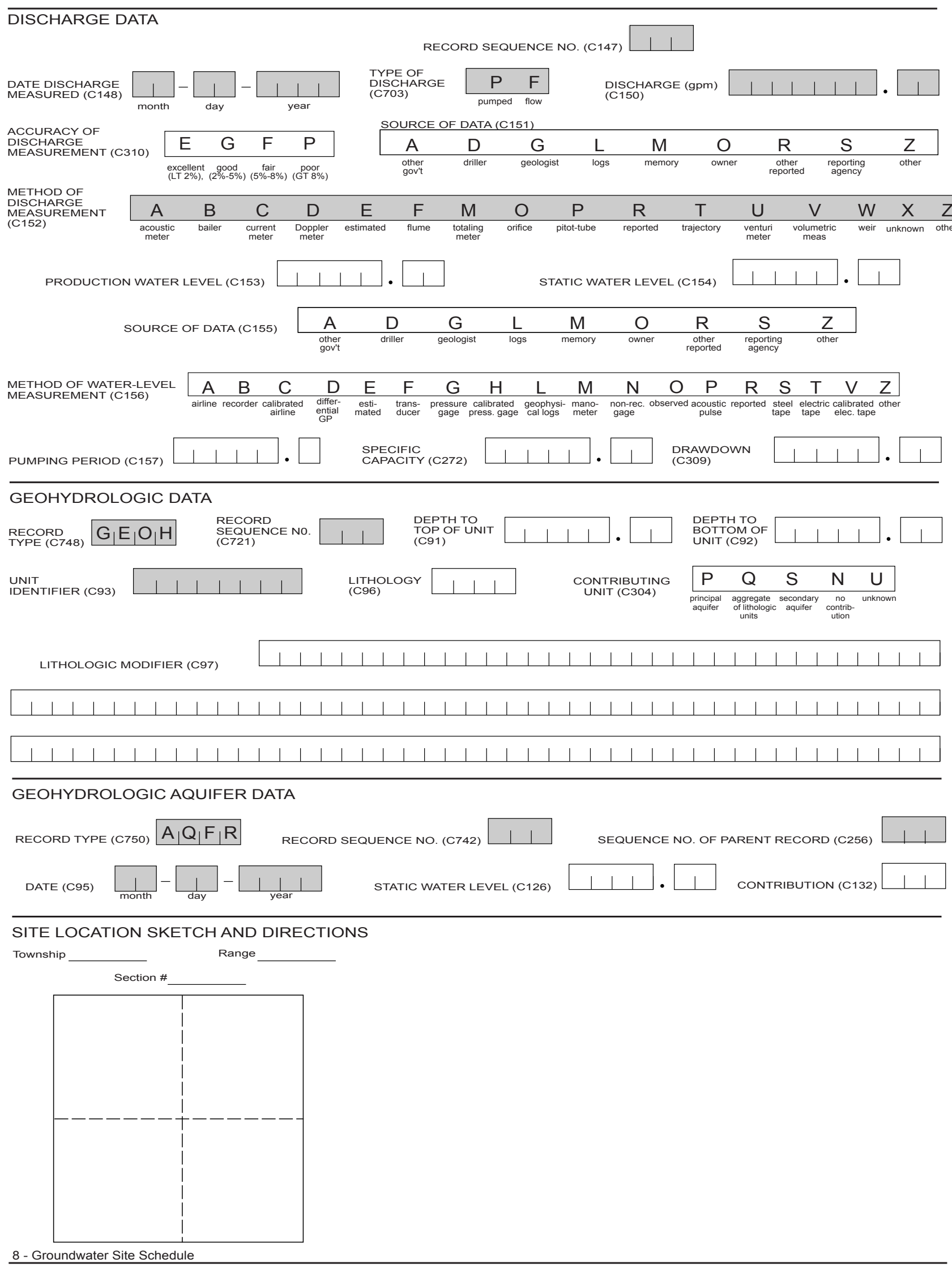

Figure 1-A.2. Form 9-1904-A-U.S. Geological Survey schedule for establishing a new groundwater site in the Groundwater Site Inventory (GWSI).-Continued 

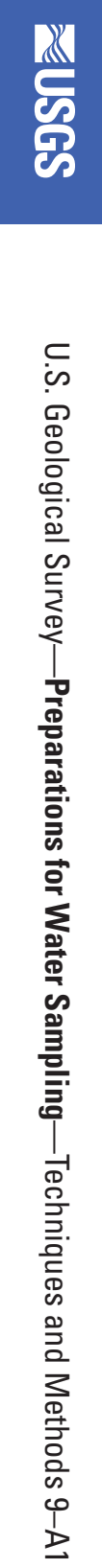